\title{
Evaluation of electrical efficiency of photovoltaic thermal solar collector
}

\author{
Mohammad Hossein Ahmadi, Alireza Baghban, Milad Sadeghzadeh, \\ Mohammad Zamen, Amir Mosavi, Shahaboddin Shamshirband, Ravinder \\ Kumar \& Mohammad Mohammadi-Khanaposhtani
}

To cite this article: Mohammad Hossein Ahmadi, Alireza Baghban, Milad Sadeghzadeh, Mohammad Zamen, Amir Mosavi, Shahaboddin Shamshirband, Ravinder Kumar \& Mohammad Mohammadi-Khanaposhtani (2020) Evaluation of electrical efficiency of photovoltaic thermal solar collector, Engineering Applications of Computational Fluid Mechanics, 14:1, 545-565, DOI: 10.1080/19942060.2020.1734094

To link to this article: https://doi.org/10.1080/19942060.2020.1734094
(c) 2020 The Author(s). Published by Informa UK Limited, trading as Taylor \& Francis Group.

曲 Published online: 26 Feb 2020.

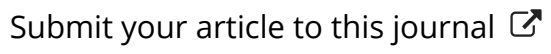

III Article views: 41

Q View related articles $\widetilde{ }$

View Crossmark data $₫$ 


\title{
Evaluation of electrical efficiency of photovoltaic thermal solar collector
}

\author{
Mohammad Hossein Ahmadia , Alireza Baghban ${ }^{b}$, Milad Sadeghzadehc, Mohammad Zamen ${ }^{a}$, Amir Mosavi $\mathbb{C}^{\mathrm{d}} \mathrm{d}, \mathrm{e}, \mathrm{f}$, \\ Shahaboddin Shamshirband (1) g, h, Ravinder Kumar' and Mohammad Mohammadi-Khanaposhtani ${ }^{j}$ \\ ${ }^{a}$ Faculty of Mechanical Engineering, Shahrood University of Technology, Shahrood, Iran; ${ }^{b}$ Chemical engineering Department, Amirkabir \\ University of Technology, Mahshahr, Iran; ' Department of Renewable Energies, Faculty of New Sciences and Technologies, University of Tehran, \\ Tehran, Iran; ${ }^{\mathrm{d}}$ Institute of Research and Development, Duy Tan University, Da Nang 550000, Vietnam; ${ }^{\mathrm{e} K a n d o}$ Kalman Faculty of Electrical \\ Engineering, Obuda University, Budapest, Hungary; ${ }^{f}$ Institute of Structural Mechanics, Bauhaus Universität-Weimar, Weimar, Germany; \\ ${ }^{9}$ Department for Management of Science and Technology Development, Ton Duc Thang University, Ho Chi Minh City, Vietnam; ${ }^{h}$ Faculty of \\ Information Technology, Ton Duc Thang University, Ho Chi Minh City, Vietnam; 'Department of Mechanical Engineering, Lovely Professional \\ University, Punjab, India; ${ }^{j}$ Fouman Faculty of Engineering, College of Engineering, University of Tehran, Tehran, Iran
}

\section{ABSTRACT}

In this study, machine learning methods of artificial neural networks (ANNs), least squares support vector machines (LSSVM), and neuro-fuzzy are used for advancing prediction models for thermal performance of a photovoltaic-thermal solar collector (PV/T). In the proposed models, the inlet temperature, flow rate, heat, solar radiation, and the sun heat have been considered as the input variables. Data set has been extracted through experimental measurements from a novel solar collector system. Different analyses are performed to examine the credibility of the introduced models and evaluate their performances. The proposed LSSVM model outperformed the ANFIS and ANNs models. LSSVM model is reported suitable when the laboratory measurements are costly and time-consuming, or achieving such values requires sophisticated interpretations.

\section{ARTICLE HISTORY}

Received 29 May 2019 Accepted 12 February 2020

\section{KEYWORDS}

Renewable energy; neural networks (NNs); adaptive neuro-fuzzy inference system (ANFIS); least square support vector machine (LSSVM); photovoltaic-thermal (PV/T); hybrid machine learning model

\section{Nomenclature}

$\begin{array}{ll}\mathrm{T}_{\text {inlet }} & \text { inlet temperature }\left[{ }^{\circ} \mathrm{C}\right] \\ \mathrm{Q} & \text { heat [watt] } \\ \mathrm{Q}_{\text {sun }} & \text { heat of sun [watt] } \\ \text { ICA } & \text { Imperialist Competitive Algorithm } \\ \text { LSSVM } & \text { Least Squares Support Vector Machine } \\ \text { NNs } & \text { Neural Networks } \\ \text { MLP } & \text { Multilayer Perceptron } \\ \text { ANFIS } & \text { Adaptive neuro-fuzzy inference system } \\ \text { RBF } & \text { Radial Basis Function } \\ \text { PSO } & \text { Particle Swarm Optimization } \\ \text { PV/T } & \text { Photovoltaic-thermal } \\ \text { MSE } & \text { Mean Squared Error } \\ \text { R } & \text { Correlation Coefficient } \\ \text { RMSE } & \text { Root Mean Square Error } \\ \text { MRE } & \text { Mean Root Error } \\ \text { STD } & \text { Standard Deviation } \\ \text { DOF } & \text { Degree of Freedom } \\ \text { BP } & \text { Back Propagation } \\ \text { GA } & \text { Genetic Algorithm } \\ \text { LMA } & \text { Levenberg-Marquardt Algorithm } \\ \text { GNA } & \text { Gausian-Newton Algorithm } \\ & \end{array}$

\section{Introduction}

Developing more efficient systems and utilizing other energy resources are taking more significance since the amount of available fossil fuel resources are facing a decreasing slope. There are several renewable energy sources that can be exploited to satisfy the energy sector demands (Qin, 2015). However, solar energy is considering more attention since it is available almost everywhere, and also it is regarded as clean energy with no harmful effect on the environment (Al-Maamary, Kazem, \& Chaichan, 2017; Bong et al., 2017; Kannan \& Vakeesan, 2016; Twidell \& Weir, 2015). Solar energy is useful for various applications, including heating, cooling, and electricity production (Ahmadi et al., 2018; Ramezanizadeh, Nazari, et al., 2018). There are two defined classifications of active and passive for utilizing solar energy. In the passive approach, there is no requirement for any extra equipment, and sun radiations utilized. While in the latter, the existence of mechanical components is necessary for solar energy utilization and the conversion process of solar energy to another form of energy is not direct. Solar collectors classified in the active approach 
of solar energy conversion to a targeted type of energy (Kannan \& Vakeesan, 2016; Lewis, 2016; Modi, Bühler, Andreasen, \& Haglind, 2017; Sijm, 2017; Wagh \& Walke, 2017). Several factors affect the performance of solarrelated systems including the absorption specifications of the applied materials, solar radiation of the region, operating condition (such as the temperature and daylight hours) and etc. (Qin, 2016; Qin, Liang, Luo, Tan, \& Zhu, 2016; Qin, Liang, Tan, \& Li, 2016). These parameters must be considered for modeling and designing solar energy technologies.

A solar collector defined as equipment which is used to gather sun-rays and absorb sunlight thermal energy and delivered it to a working fluid, mostly air or water. The transferred thermal energy in the working fluid can be stored in a storage tank to be used when solar energy is not sufficient or is not available (e.g. during the nights). Photovoltaic panels use solar irradiations and produce electricity. Moreover, during this electricity production process, a considerable amount of waste heat is also generated which can be taken its benefit by integrating a network of tubes which containing a fluid for heat transfer process (Ahmad, Saidur, Mahbubul, \& Al-Sulaiman, 2017; Kumar, Prakash, \& Kaviti, 2017).

The photovoltaic panels or so-called solar thermal collectors transform solar energy to the convenient electrical energy. Photovoltaic collector (PV) cells are challenged with low efficiency due to the high heat. Yet, the novel design of the electrical-thermal interaction in a hybrid photovoltaic/thermal (PV/T) collector is reported as an alternative to increase efficiency through heat dissipation (Pandey et al., 2016).

Solar collectors categorized into two classifications based on the tracking model: no tracking system installed, fixed collectors, and a tracker system provided for tracking the sunlight during the daylight, tracking collectors. There is no movement for the fixed collectors, while the tracking collectors move in a way where the incoming sun-rays are perpendicular to the surface of the collectors. Flat plate collectors, evacuated tube collectors are classified as the fixed collector. There are two subclasses of single-axis tracking and double axis tracking for tracking of solar collectors. The former classified into three groups of parabolic and cylindrical trough collectors and linear Fresnel collectors. The latter examples are central tower collectors, parabolic dish collectors, and circular Fresnel lenses. All of the mentioned technologies have their specific applications based on the feasibility of the required and available amount of energy demand and also some other climatic considerations (Fuqiang et al., 2017; Hussain et al., 2013; Pandey \& Chaurasiya, 2017).

Predictive models are widely used for pattern recognition and estimating the behavior of various systems and technologies (Qin, Liang, Tan, \& Li, 2017; Ramezanizadeh, Alhuyi Nazari, Ahmadi, Lorenzini, \& Pop, 2019; Ramezanizadeh, Ahmadi, Ahmadi, \& Alhuyi Nazari, 2018). Currently, several methods are developed to predict the quantity of solar energy production. The primary methods classified in the two approaches of the cloud imagery integrated with physical models and machine learning approaches. The prediction horizon is the distinction making factor for selecting between the methods. However, there is no unity for all methods predictions, and the accuracy and precision are different. Different methods developed for solar irradiance prediction based on the favorite prediction time (Burrows, 1997; Marquez \& Coimbra, 2011; Moreno, Gilabert, \& Martínez, 2011; Podestá, Núñez, Villanueva, \& Skansi, 2004; Tso \& Yau, 2007).

Recently, the advantages of several PV/T collector systems highlighted in the investigations (Pandey et al., 2016). The market development of various solar thermal collectors was studied and compared with PV solar farms (Kramer \& Helmers, 2013). To avoid time-consuming and also expensive experimental examinations in the PV/T systems, soft machine-based forecasting methods are developed (Chau, 2017; Chuntian \& Chau, 2002; Fotovatikhah et al., 2018; Hajikhodaverdikhan, Nazari, Mohsenizadeh, Shamshirband, \& Chau, 2018; Taherei Ghazvinei et al., 2018; Wu \& Chau, 2011). These models can forecast the output efficiently based on some required input data. The data are then trained based on the algorithms to predict the desired output. Utilizing artificial intelligence becomes popular in the fields of heat transfer, e.g. the thermal performance of solar air collectors have been predicted through an ANN approach where the model reported showed promising results (Caner, Gedik, \& Keçebaş, 2011). Varol et al. (Varol, Koca, Oztop, \& Avci, 2010) modified the prediction technique; They evaluated three soft computing techniques of ANN, Support Vector Machines (SVM), and ANFIS to forecast the thermal performance of the solar air collectors.

Now, modern computational techniques are developed for optimization purposes, finding the governing functions or solution of actual engineering problems in different disciplines (Baghban, Bahadori, Lemraski, \& Bahadori, 2015; Baghban, Kashiwao, Bahadori, Ahmad, \& Bahadori, 2016; Baghban, Sasanipour, \& Zhang, 2018; Bahadori et al., 2016; Haratipour, Baghban, Mohammadi, Nazhad, \& Bahadori, 2017).

Since the calculation of the thermal efficiency by conventional solution methods results in solving complicated mathematical differential equations that are time consuming, the use of machine learning methods is considered. These methods can provide accurate prediction of the studied process by saving time and cost 
compared to laboratory methods. In this research, softcomputational techniques were employed to forecast the efficiency of $\mathrm{PV} / \mathrm{T}$ collector. These selected approaches are namely, MLP-ANN, ANFIS, and LSSVM. The sun heat, flow rate, inlet temperature, and solar radiation are considered as the inputs variables for training and testing machine learning models to study the electrical efficiency yield as the output.

\section{Theory}

\subsection{The adaptive neuro-fuzzy inference model}

The momentum duty of the adaptive neuro-fuzzy inference (ANFIS) is to discover for fuzzy decision guidelines in the feed-forward framework. The establishment of conventional ANFIS based on 1st order Takagi-Sugeno inference model is demonstrated in the following figure, Figure 1.

The ANFIS model states that a primary regulation made of 5 layers. As shown in Figure 1, inputs of $x$ and $y$ fed into the built model, and the following output of $f$ has resulted. In this mode, two different if-then fuzzy statements defined as follows (Brown \& Harris, 1994; Lin \& Lee, 1996):

$$
\begin{aligned}
& \text { Rule } 1 \text { : If } x \text { is } \alpha 1 \text { and } y \text { is } \beta 1 \text {; then } f 1 \\
& \quad=m 1 x+n 1 y+r 1
\end{aligned}
$$

Rule 2 : If $x$ is $\alpha 2$ and $y$ is $\beta 2$; then $f 2$

$$
=m 2 x+n 2 y+r 2
$$

Where $\alpha_{1}, \alpha_{2}, \beta_{1}$, and $\beta_{2}$ are the fuzzy sets for $\mathrm{x}$ and $\mathrm{y}$. Furthermore, the variables of $m_{1}, n_{1}, r_{1}, m_{2}, n_{2}$, and $r_{2}$ represent the final outputs of the training workflow.
The node functions are defined in every layer as follows:

Layer $I$ is the fuzzification of the task. Each node $i$ represents an adaptive node. The outcome of each node in this layer is:

$$
\begin{aligned}
& O_{1, i}=\mu_{\alpha i}(x) \quad \text { for } i=1,2 \\
& O_{1, i}=\mu_{\beta_{(i-2)}}(y) \quad \text { for } i=3,4
\end{aligned}
$$

$x$ and $y$ are the node's input data, $i . \mu_{\alpha i}$ and $\mu_{\beta i}$ are functions for the fuzzy membership.

Layer II: devoted to managing the layer and nodes with constant $(i=M)$. The receiving signals are consequently produced and resulted in the output. The output calculated by applying the following equation:

$$
O_{2, i}=W_{i}=\mu_{\alpha i}(x) \mu_{\beta i}(y) \quad \text { for } i=1,2
$$

Layer III is defined as the normalization layer. The normalized data of the $i^{t h}$ node, N, calculate the normalized strength as follows:

$$
O_{3, i}=\bar{w}_{i}=\frac{W i}{W 1+W 2} \quad \text { for } i=1,2
$$

Layer IV is configured to de-fuzzy the data. Where between every node $i$ and a node function, an adaptive relation is defined:

$$
O_{4, i}=\bar{w}_{i} f_{i}=\bar{w}_{i}\left(m_{i} x+n_{i} y+r_{i}\right)
$$

The parameter sets of this node are $m_{i}, n_{i}$ and $r_{i}$, respectively.

Layer $V$ is the final layer. The overall output of all receiving signals are calculated by a fixed node of $\mathrm{E}$ in

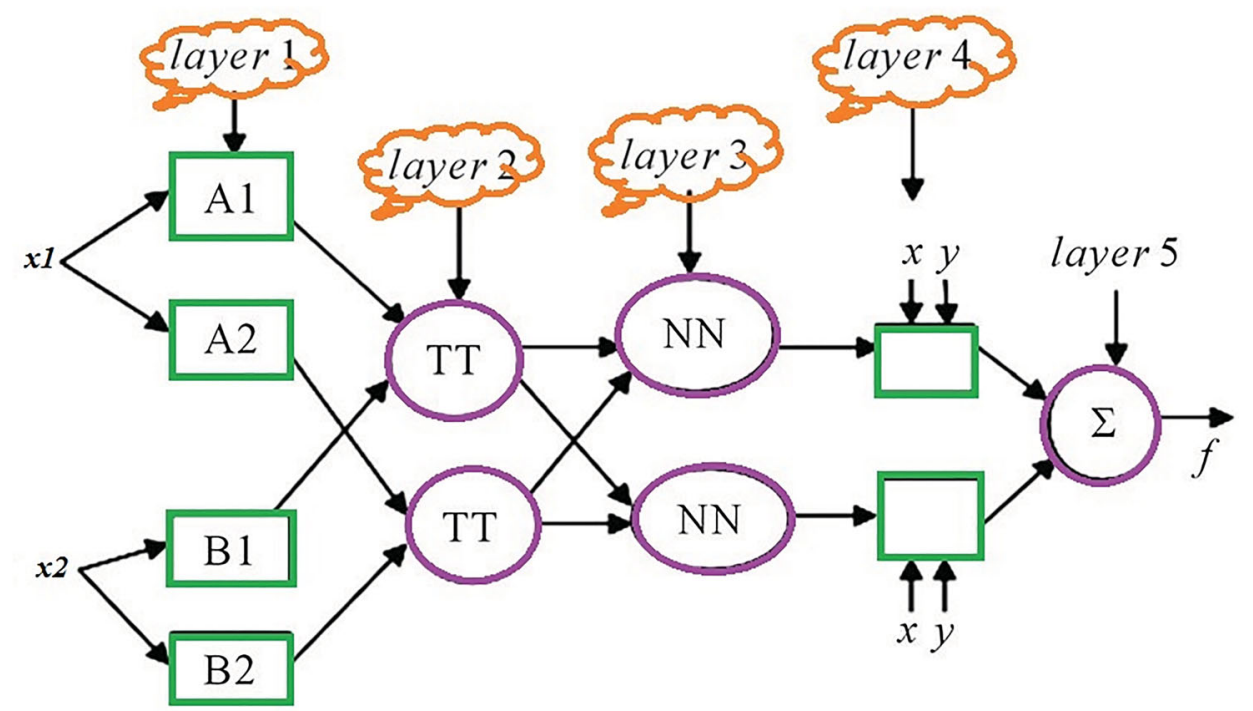

Figure 1. Establishment of typical ANFIS. 
this layer and then are summed:

$$
O_{5, i}=\sum_{i} w_{i} f_{i}=\frac{\sum_{i} w_{i} f_{i}}{\sum_{i} w_{i}}
$$

As mentioned above, the tuning parameters in the ANFIS structure are its membership parameters. These parameters can be determined optimally using evolutionary and optimization algorithms, e.g. PSO, GA, ACO, ICA. In the current study, these parameters are optimized using the PSO algorithm.

\subsection{The multi-layer perceptron artificial neural network model}

The ANNs are composed of a several internal, external, and hidden neural layers (Mitchell, 1997; Schalkoff, 1997; Yegnanarayana, 2009). Each layer includes some nodes which called as neurons. Every neuron connected through an interconnection relationship. A weighted parallel connecting establishment is made to treat these relationships. Multilayer recurrent, RBF, and MLP are among the popular ANNs. A general layout of the multi-layer ANN demonstrated in Figure 2.

The two essential parameters in the ANN problems are weight and bias. Weight values perform the interconnections throughout the neurons. Moreover, the bias parameter is used to specify the system's degree of freedom (DOF). In the ANN arrangement, the output of every single layer summed with the values of biases. Then, in order to convert and send the obtained signals to the next layer, the transfer function must be used. Linear, Sigmoid, and Hyperbolic tangent functions are known as the most typical transfer function in ANN structures:

Linear function : $f(z)=z$

Sigmoid function : $f(z)=\frac{1}{1+e^{-z}}$

Hyperbolic tangent function : $f(z)=\frac{e^{z}-e^{-z}}{e^{z}+e^{-z}}$

In this investigation, the Sigmoid transfer function, Equation (10), is employed in the hidden layer and the Linear transfer function, Equation (9), is applied in the output layer. Thus, the model outcome obtained as (Haykin, 1994; Haykin, Haykin, Haykin, \& Haykin, 2009):

$$
Z=\sum_{i=1}^{n} w_{3 i} \frac{1}{1+e^{-\left(x_{i} w_{i}\right)}}+b_{3}
$$

Where, $\mathrm{w}_{\mathrm{i}}$ denotes the weight values, $\mathrm{n}$ represents the number of neurons in the hidden layer, $\mathrm{w}_{\mathrm{i}, 3}$ indicates the weight values and $b_{3}$ is the bias. The outcome named $\mathrm{Z}$.

Moreover, the layout of the ANN is trained and is gone through an optimization process by utilizing the Back Propagation (BP) algorithm. During the training stage, the optimum statuses of weights and biases calculated. While biases and weights reach their optimum values, the disparity of the prediction of the ANN model and the real measured data is minimized. The value of the prediction error is obtained as:

$$
E=\sum_{P} E(\omega)=\sum_{P} \sum_{i}\left(r_{i}^{P}-O_{i}^{P, i}\right)
$$

where, $\mathrm{p}, O_{i}^{P, i}$, and $r_{i}^{P}$ indicate the quantity of the training data, the $\mathrm{i}^{\text {th }}$ neuron which belongs to the $\mathrm{l}^{\text {th }}$ output layer, and the $\mathrm{i}^{\text {th }}$ real output corresponding to the $\mathrm{p}^{\text {th }}$ training data, respectively.

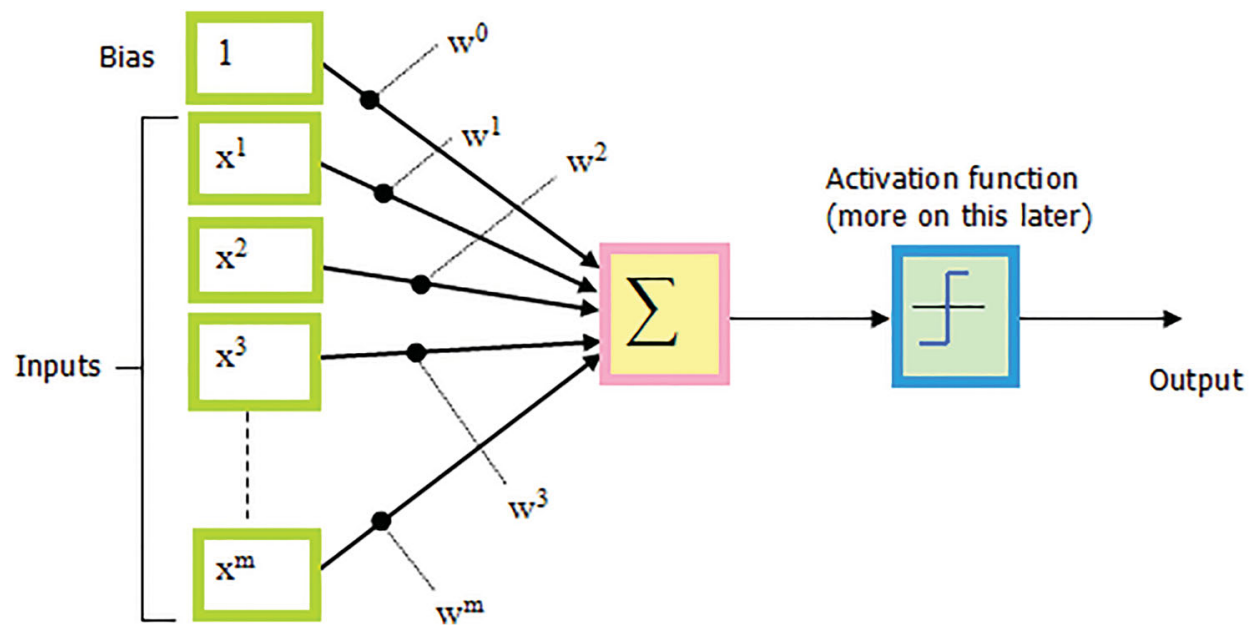

Figure 2. Construction of MLP-ANN model. 
Based on Equation (14) moreover, Equation (15), BP algorithm is used to transfer the bias terms and also the weight's terms:

$$
\begin{aligned}
\omega_{i, j}^{i-1, l}(k+1) & =\omega_{i, j}^{i-1, l}(k)-\lambda \frac{\partial E}{\partial \omega_{i, j}^{i-1, j}} \\
b_{j}^{l}(k+1) & =b_{j}^{l}(k)-\lambda \frac{\partial E}{\partial b_{i}^{l}}
\end{aligned}
$$

Here, $\lambda$ indicates the learning rate, and $\mathrm{k}$ states the iteration numbers.

\subsection{The radial basis function artificial neural network model}

The process of the radial basis function artificial neural networks (RBF-ANNs) is demonstrated in Figure 3. There are many interconnected neurons in the RBFANNs. It composed of 3 layers of input, hidden layers, and output (Wasserman, 1993). The input layer's task is to import the input parameters into the transfer function. The number of model input parameters is equal to the number of nodes in the input layer. The hidden layer is the most noticeable part of the RBF-ANNs. Radially symmetry is a prominent feature of these nodes in this layer. Finally, by applying the weight factor from the output layer node to the hidden layer node, the output of this model is generated.

The MLP is structurally analogous to RBF-NNs. However, the calculation process is not similar since, in the RBF-NNs, one hidden layer exists, uses, and estimates in the calculation process, but the MLP-NNs employ multiple hidden layers that are interconnected. Before applying the RBF-NNS, an activation function of the hidden layer defined, and the highest quantity of the neurons specified. Here, neurons considered as a processing unit of the network. Besides, the assessment of the optimum values is a crucial task in the process of modifying the process based on the assessment. Weight factors are used to train the RBF-NNs (Park \& Sandberg, 1993).

The essential traits of the RBF-NNs are listed as follows:

- Triple-layer structure.

- Activation functions of Gaussian used in the hidden layer.

- Weight delivered to the hidden layer and then assigned to the output layer.

- An acceptable degree of interpolation.

In the interpolation algorithm, the input data mapped to the corresponding objective value of $\mathrm{t}^{\mathrm{p}}$. Thus, each input vector required an activation function. This process performed by $\phi\left(x-x^{p}\right)$. Here, $\phi$ is the activation function and $x-x^{p}$ denotes the Euclidean position difference between $x$ and $x^{p}$. The output is calculated as follows:

$$
f(x)=\sum_{p=i}^{N} w_{p} \phi\left(x^{q}-x^{p}\right)=t^{p}
$$

Where, $w_{p}$ is the weight factor and $x^{q}$ denotes the $\mathrm{q}^{\text {th }}$ input vector. In other words, to regulate the weight terms to come close to the Equation (17), the interpolation process is necessary:

$$
f\left(x^{q}\right)=\sum_{p=i}^{N} w_{p} \phi\left(x^{q}-x^{p}\right)=t^{p}
$$

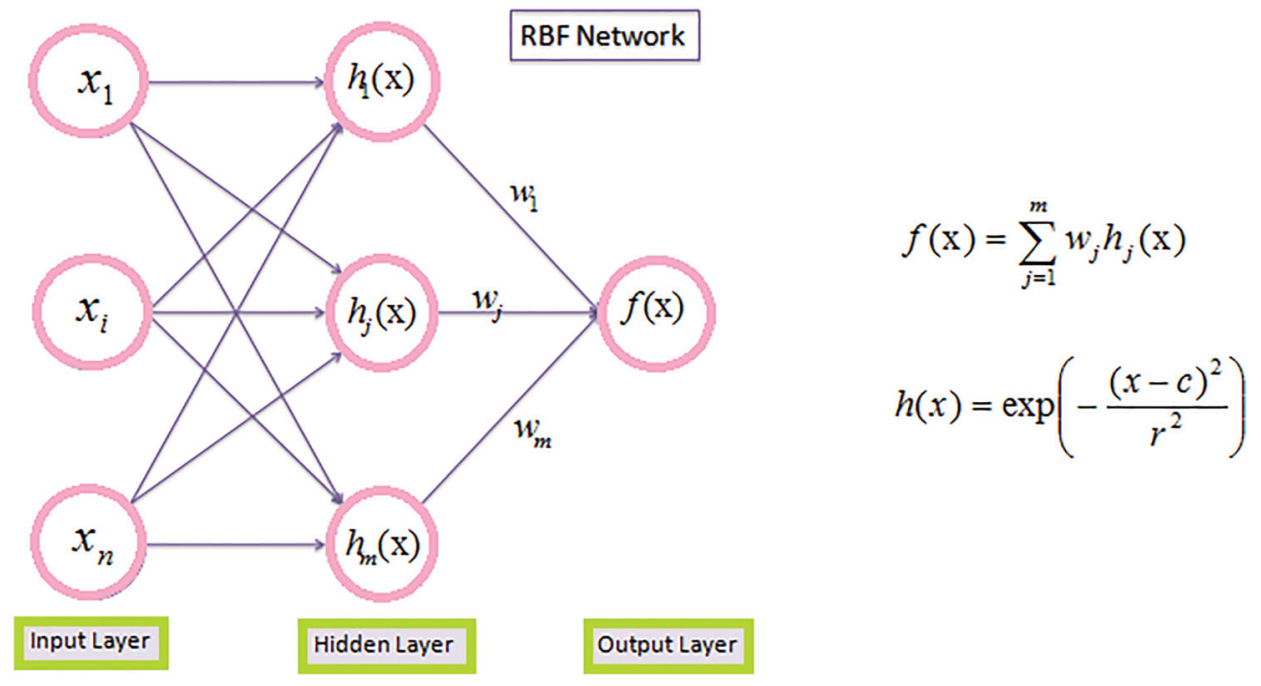

Figure 3. Construction of the RBF-ANN approach. 
Among available activation functions, the Gaussian activation function is mostly used. This function is defined as follows:

$$
\phi(r)=\exp \left(-\frac{r^{2}}{2 \sigma^{2}}\right)
$$

where, $\sigma$ and $\mathrm{r}$ denote the interpolating function and the distance between a center of ' $c$ ' and the local position of data point ' $x$ ', respectively.

\subsection{The least square support vector machine model}

Support Vector Machine (SVM) considered as a unique tool since its full practicality in various cases. SVM has several features, including wider converge to find the precious optimum, no further network regulation is required, lower regulation parameters, and more flexibility in overfitting issues. The following function can be considered for the SVM theory (Pelckmans et al., n.d.; Suykens, Van Gestel, De Brabanter, De Moor, \& Vandewalle, 2002; Ye \& Xiong, 2007):

$$
f(x)=w^{T} \emptyset(x)+b
$$

$\phi(x)$ and $W^{T}$ substitute the kernel function and the output layer vector, respectively. Furthermore, $\mathrm{b}$ and $\mathrm{x}$ represent the bias, and the inputs into the $N \times n$ matrix, respectively. In this matrix, the $\mathrm{N}$ denotes the trained data and $\mathrm{n}$ states the input parameters' number. Vapnik presented a meticulous procedure to obtain weight and bias. In this process, the following function must be minimized (Vapnik, Golowich, \& Smola, 1997):

$$
\text { Objective Function }=\frac{1}{2} w^{T}+c \sum_{i=1}^{n}\left(\xi_{i}-\xi_{i}^{*}\right)
$$

By these following restrictions:

$$
\left\{\begin{array}{c}
y_{k}-w^{T} \emptyset\left(x_{k}\right)-b \leq \varepsilon+\xi_{k}, k=1,2, \ldots, N \\
w^{T} \emptyset\left(x_{k}\right)+b-y_{k} \leq \varepsilon+\xi_{k}{ }^{*}, k=1,2, \ldots, N \\
\xi_{k}, \xi_{k}^{*} \geq 0
\end{array}\right.
$$

In the above equations, $x_{k}$ is the $\mathrm{k}^{\text {th }}$ input, $y_{k}$ indicates the $\mathrm{k}^{\text {th }}$ output, $\varepsilon$ indicates the accuracy of the function estimation, $\xi_{k}$ and $\xi_{k}^{*}$ denote the slack factors. In overall, in order to specify the allowable deviations, slack terms are employed. A modifiable term of $c>0$ requires to adjust the value range of the deviation from the $\epsilon$.

SVM method is modified to Least Square Support Vector Machine (LSSVM) to be able to cover linear equations through linear programming to get a faster and more curious response than the conventional SVM approach.
The LSSVM approach is as follow:

$$
\text { Objective Function }=\frac{1}{2} w^{T} w+\frac{1}{2} \gamma \sum_{k=1}^{N} e_{k}^{2}
$$

While:

$$
y_{k}=w^{T} \emptyset\left(x_{k}\right)+b+e_{k}
$$

In the above equations, the training parameter denoted by $\gamma$ and the regression error of the training steps is represented by $e_{k}$.

Moreover, in comparison with the SVM method, equality constraints are used instead of the inequality constraints. The Lagrangian approach is used to solve the above problem (Equation (22) and Equation (23)):

$$
\begin{aligned}
L(w, b, e, a)= & \frac{1}{2} w^{T} w+\frac{1}{2} \gamma \sum_{k=1}^{N} e_{k}^{2} \\
& -\sum_{k=1}^{N} a_{k}\left(w^{T} \emptyset\left(x_{k}\right)+b-e_{k}-y_{k}\right)
\end{aligned}
$$

Here, $a_{k}$ indicates the Lagrangian multipliers and its derivatives should be equal to zero for solving the process. Furthermore, the following equations of Equation (25) should be employed:

$$
\left\{\begin{array}{c}
w=\sum_{k=1}^{N} a_{k} \emptyset\left(x_{k}\right) \\
\sum_{k=1}^{N} a_{k}=0 \\
a_{k}=\gamma e_{k}, k=1,2, \ldots, N \\
y_{k}=w^{T} \emptyset\left(x_{k}\right)+b+e_{k}, k=1,2, . ., N
\end{array}\right\}
$$

Therefore, the LSSVM method should be applied to solve the $2 \mathrm{~N}+2$ equations and other unknown variables of $e_{k}, a_{k}, \mathrm{w}$, and b. $\gamma$ indicates the regulating variable of the LSSVM approach. Since both of SVM and LSSVM methods are used kernel functions, the presence of other tuning parameters is essential. Here, RBF kernel has been employed:

$$
k\left(x, x_{k}\right)=\exp \left(\frac{-x_{k}-x^{2}}{\sigma^{2}}\right)
$$

$\sigma^{2}$ is acted as a regulating parameter. Therefore, the target parameters of the LSSVM can be obtained more precisely by decreasing the error between the predicted results and the actual illustrations. For the LSSVM approach; the mean square error (MSE) is presented as follows:

$$
M S E=\frac{\sum_{i=1}^{n}\left(\alpha_{i, \exp }-\alpha_{i, \text { pred }}\right)^{2}}{n}
$$

$\mathrm{n}$ denotes the quantity of the primary population, $\alpha$ states the output amount of $\mathrm{CO}_{2}$. The subscript Pred. stands for 
Encoding potential solutions (chromosomes)

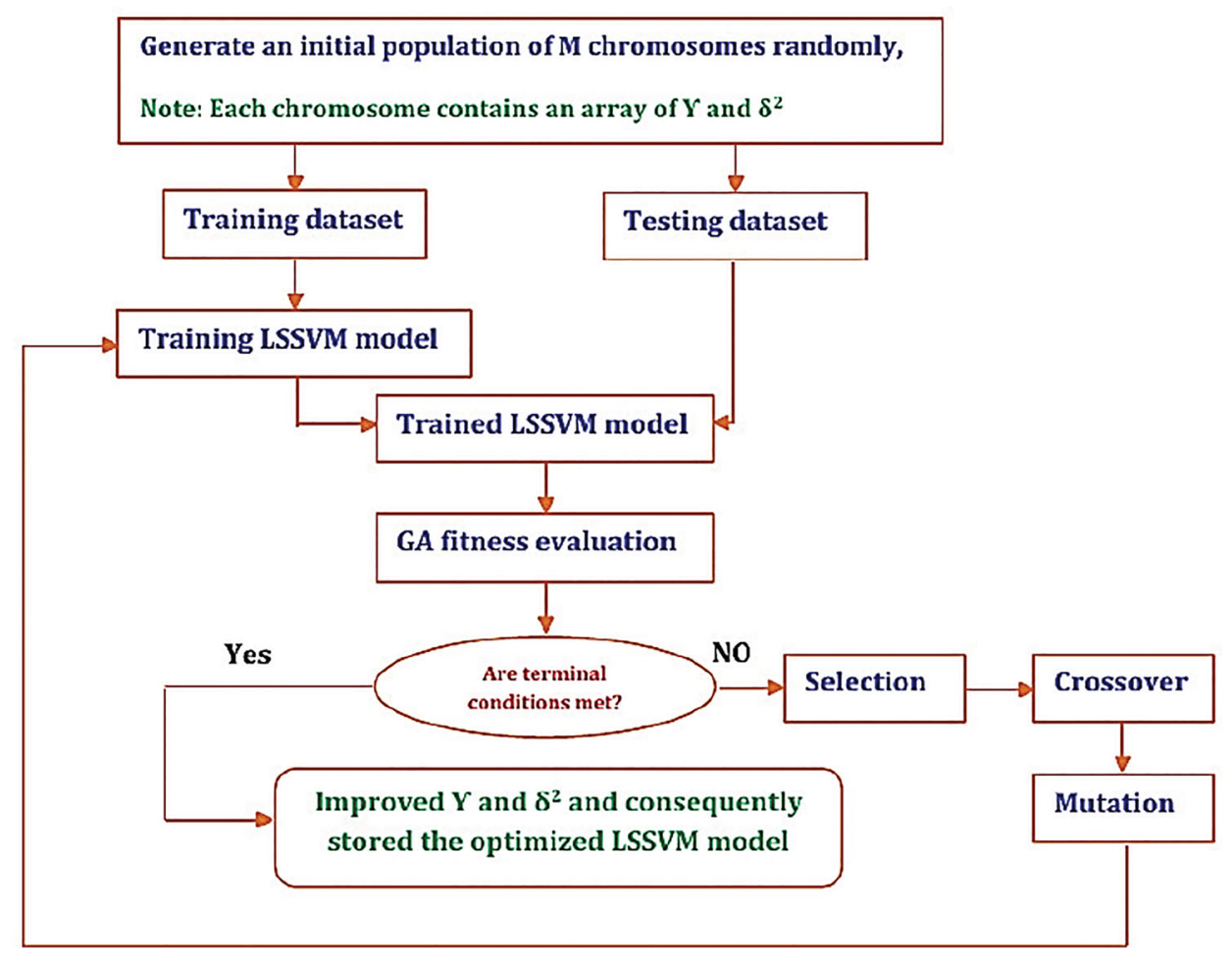

Figure 4. The LSSVM-GA model.

predicted data points and exp. is the experimental data points.

Here, LSSVM model is applied and the Genetic Algorithm (GA) is utilized in order to perform an optimization to regulate the parameters of the LSSVM (Suykens et al., 2002). The schematic diagram of the LSSVM technique illustrated in Figure 4 . In this procedure, the data points are classified into two subclasses: train and test datasets in the first stage. The LSSVM network is composed based on the training data. $\sigma^{2}$ and $\gamma$ are arbitrarily guessed and then GA modified the values by means of minimizing the MSE between the real output and predicted value. This algorithm is performing continuously to obtain the desired objectives.

\section{Experimental procedure and data Preparation}

Data was gathered from a laboratory scale PV/T setup that has a new design in layering of the thermal section. As presented in Figure 5(a) a half pipe is used instead of full circle tube as the fluid channel that is bonded to the absorber plate using special adhesives. This design leads to direct contact of water with the absorber plate. This configuration reduces the thermal resistance of the layers which significantly improves heat transfer from the cells to the fluid. Half pipe mounted behind the absorber plate in a serpentine path that shows in Figure 5(b). The flowrate and inlet/outlet temperature of the fluid was

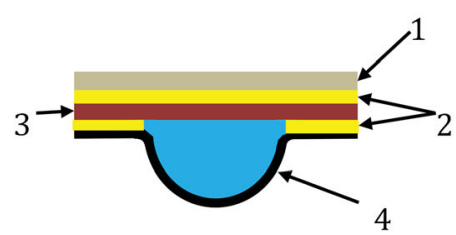

(a)

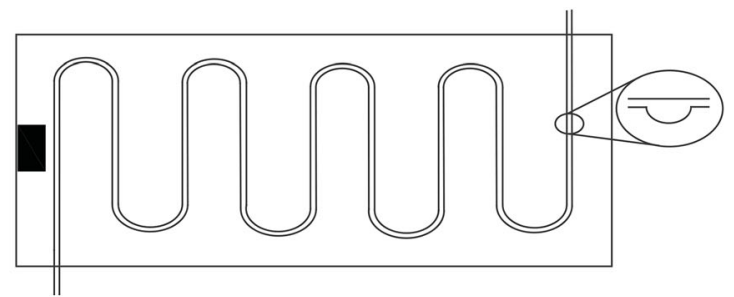

(b)

Figure 5. (a) Cross section of Fluid Channel (1:Glass, 2:Adessive, 3:Absorber Plate, 4:Aluminium Half Pipe) (b)serpentine path of half pipe on the back of the panel. 

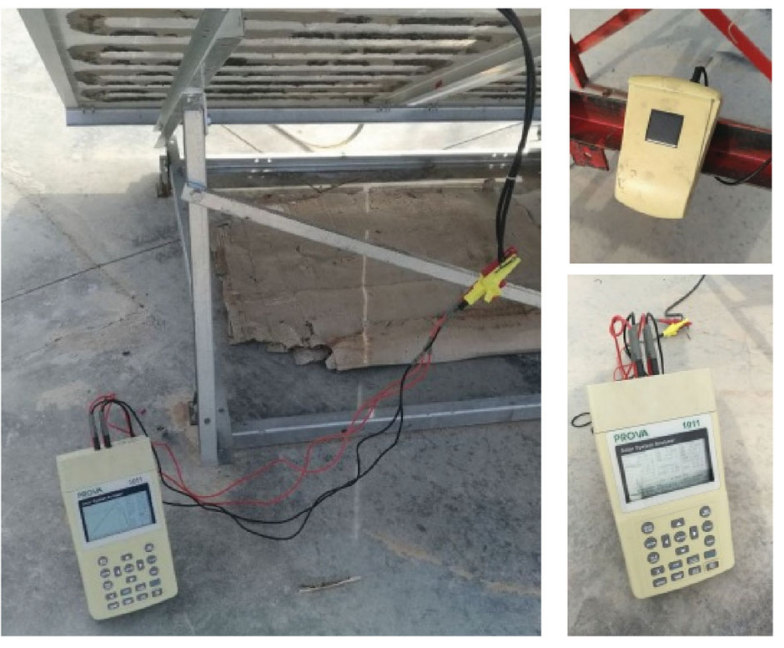

Figure 6. Solar system analyzer and it's connection to the PV/T panel.

measured to evaluate the thermal energy gain from the $\mathrm{PV} / \mathrm{T}$ panel.

A PV panel with 36 cells (with 9 rows and 4 columns) has been used for this purpose. Aperture area and nominal efficiency of the panel (under standard condition) are $0.7 \mathrm{~m}^{2}$ and $12.5 \%$, respectively. Also it has an open circuit voltage $\left(\mathrm{V}_{\mathrm{oc}}\right)$ of $22.2 \mathrm{~V}$ and short circuit current $\left(\mathrm{I}_{\mathrm{sc}}\right)$ of 5.5A.

Water is circulated with a pump and it's flow rate is controlled with a manual ball valve and measured by a rotameter in range of $0.5-4$ liters per minute. Inlet and outlet temperature are measured with a K-type thermocouple (with accuracy of $\pm 0.1^{\circ} \mathrm{C}$ ). Also, the output and solar radiation data can be measured and recorded by a solar system analyzer. As shown in Figure 6 the PROVA 1011 Solar System Analyzer is used to measure the electrical characteristics of the solar panel. This device measure the solar radiation by a photovoltaic pyranometer that shown in Figure 6. Also it indicates the I-V curve, maximum solar panel power and related voltage and current to this point and the present efficiency of the solar panel.

The system was tested on sunny summer days almost in the noon to have the constant and maximum amount of solar irradiations. In addition to the above parameters, the ambient temperature and wind velosity was measured for entering to the model. The effect of the inlet temperature and flow rate of the water stream on the electrical and thermal efficiency was evaluated.

The system was experimented on a sunny summer day almost in the noon to have the constant and maximum amount of solar irradiations. The variations of solar irradiance during the tests on different days are illustrated in Figure 7.

The water mass flow rate is an essential factor in the $\mathrm{PV} / \mathrm{T}$ system. In this study, the water mass flow rate is $\frac{1}{2}$ to $4 \mathrm{lit} / \mathrm{min}$ and other system parameters are recorded. Also, the influence of water inlet temperature $\left(20^{\circ} \mathrm{C}<\mathrm{T}_{\text {inlet }}<\right.$ $45^{\circ} \mathrm{C}$ ) on the $\mathrm{PV} / \mathrm{T}$ system has experimented.

Figure 8 demonstrates the parallel diagram of affecting parameters and their ranges at various heat of the sun on the PV/T system. Figure 9 illustrates Andrews diagram of all parameters to have a visual insight from highdimensional data. For plotting these diagrams, Andrews tool is used in MATLAB 2018 library. This diagram is a non-integer model of the Kent-Kiviat radar diagram or

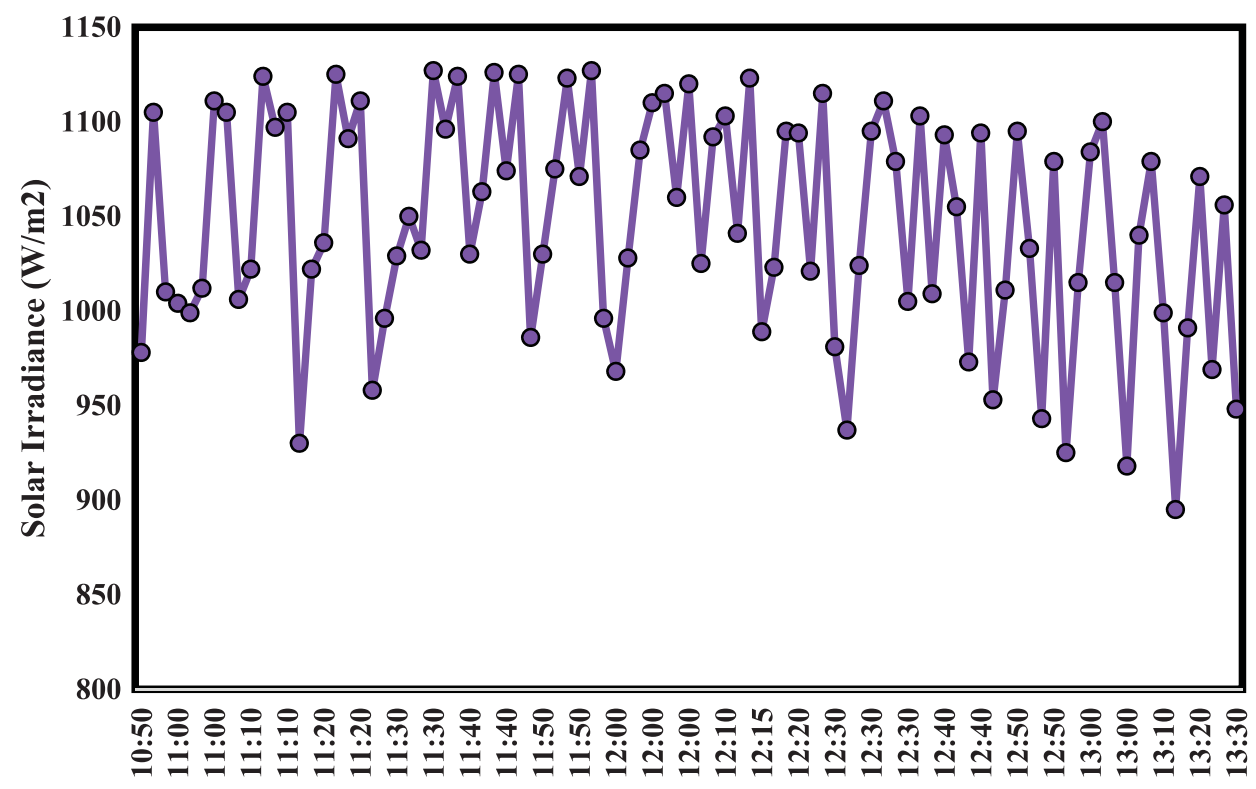

Time

Figure 7. Data set for solar irradiance. 


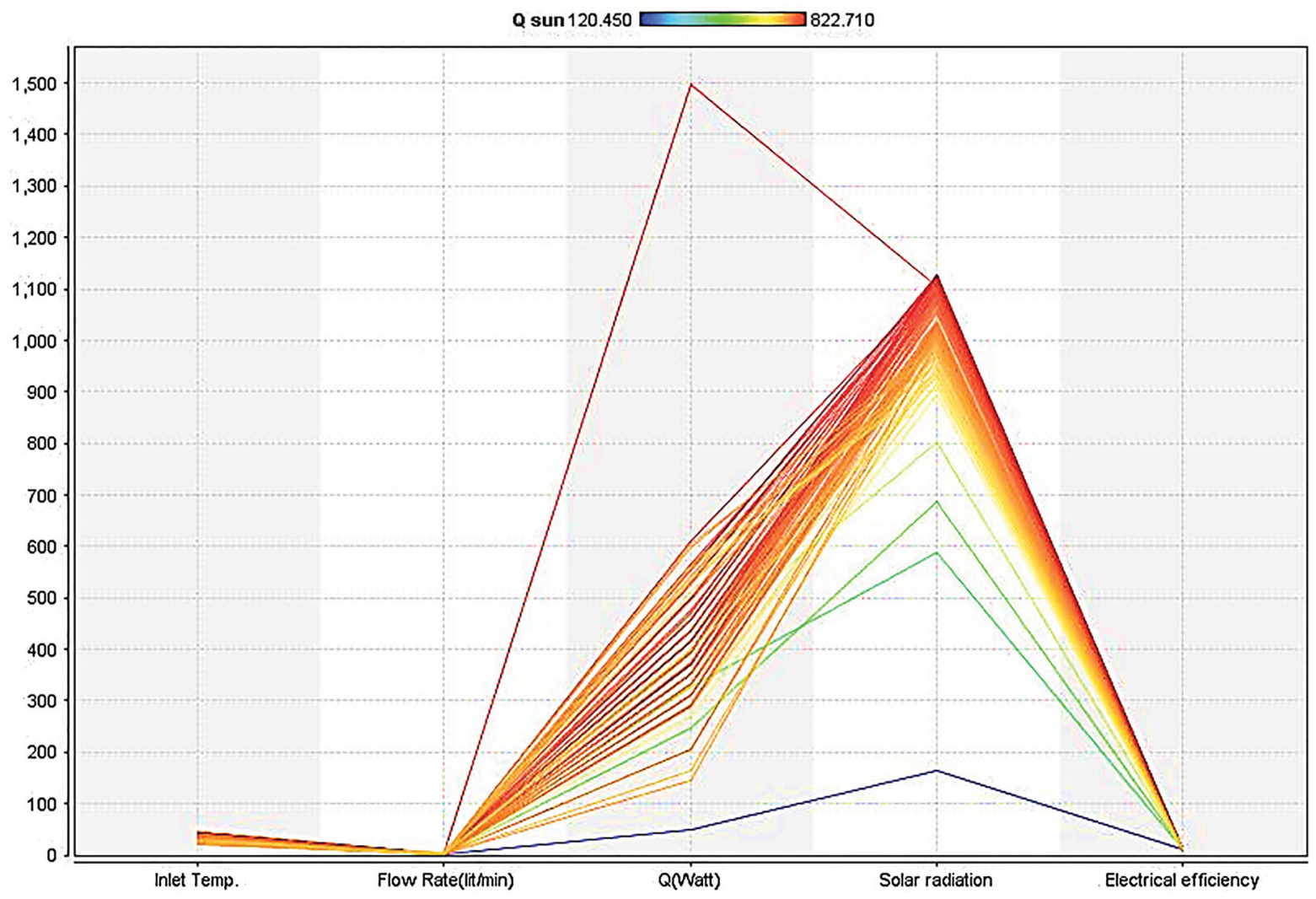

Figure 8. Parallel diagram of studied parameters in the present study of efficiency measurement of a PV/T collector.

the smoothened model of a parallel coordinate diagram (Andrews, 1972). Curves belonging to samples of a similar class will usually be closer together and their behavior is similar. As can be seen in this figure, since the Andrews diagrams of the inlet temperature, heat, solar radiation, the heat of the sun, and electrical efficiency are very close together, these parameters behave similarly, while flow rate behaves very differently.

Moreover, a proper tool for evaluation of rough linear correlations of metadata is scatter plot matrices. For all of the applied parameters of this study, the scatter plot was drawn and illustrated in Figure 10. In this figure, all of the parameters placed diagonally. Each parameter plotted against other parameters. The more the parameters of a plot are related to each other, the less scattered the points within that plot. For example, according to this Figure, heat of sun has a relatively good linear relationship with solar radiation, while electrical efficiency and flow rate are not linearly correlated.

\section{Models Implementation}

\subsection{Preprocessing procedure}

Four machine-based prediction models of MLP-ANN, RBF-ANN, ANFIS, and LSSVM were developed in
Matlab 2018 software to model the efficiency of the PV/T system. In order to find the objective of the efficiency of the PV/T system, some affecting parameters are assumed to be known and inserted as an input to the model. These variables are inlet temperature, flow rate, heat, solar radiation, and heat of the sun. An overall number of 98 data points were utilized in the models above to forecast the desired objective.

The data classified into two subclasses of train and test, which $75 \%$ of the data considered as training and the remaining belong to the test subclass. The former is used to specify the external variables of the developed models, while the latter checks the precision of the model's output. To have a homogenized data set, the following equation, Equation (28) is used to normalize the data points in the normalization range of $[-1,1]$ :

$$
D_{n}=2 \frac{D-D_{\min }}{D_{\max }-D_{\min }}-1
$$

$\mathrm{D}$ is the variable, $\mathrm{n}$ stands for normalized, min refers to a minimum, and max states the maximum amounts of the corresponding variable. In these models, inlet temperature, flow rate, heat, solar radiation, and heat of the sun are the input of the problem while the electrical efficiency is designed to be the target objective. 

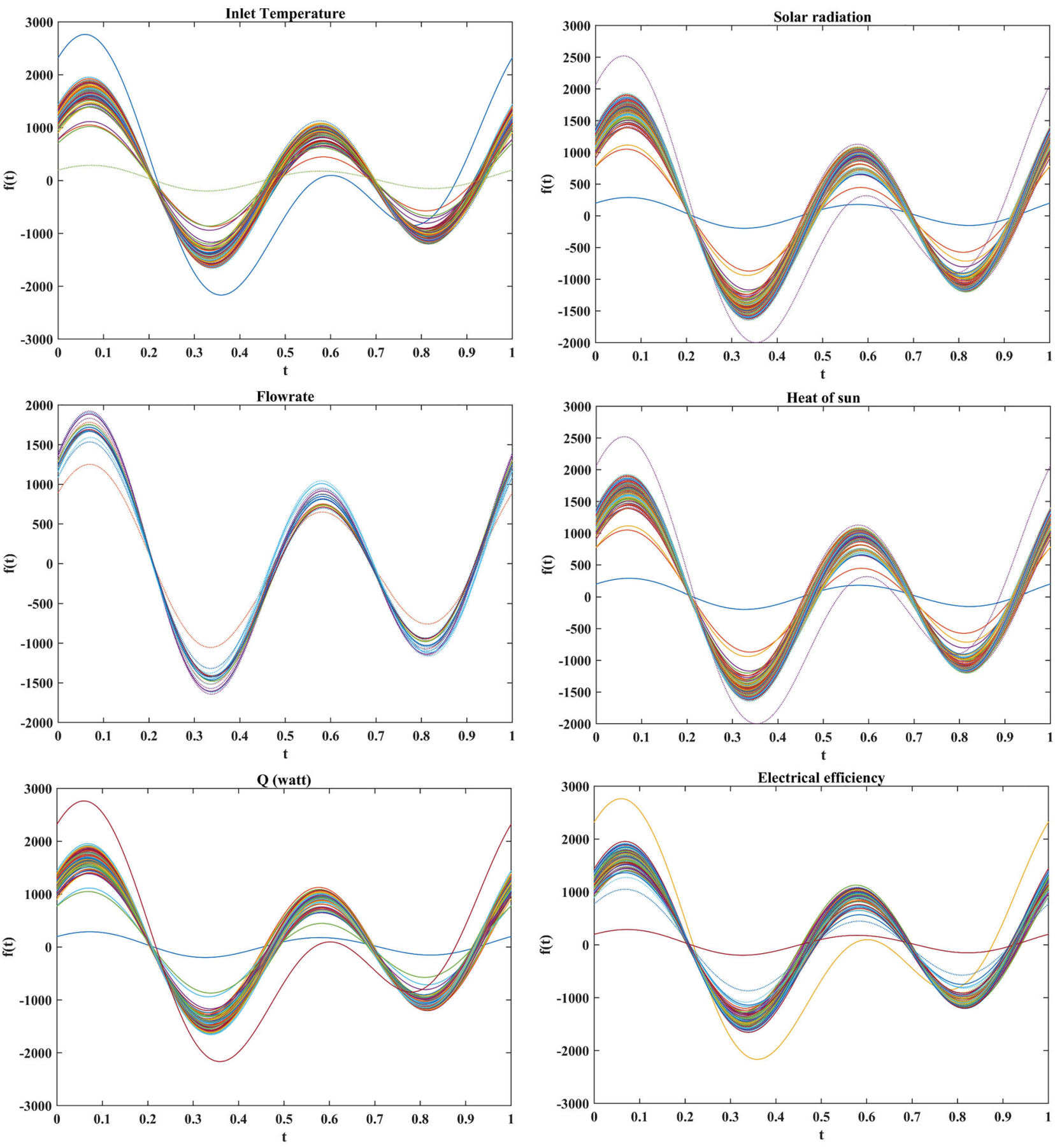

Figure 9. Andrew plots of variables including inlet temperature, flow rate, heat, solar radiation, heat of the sun, and electrical efficiency.

\subsection{Model Development}

\subsubsection{ANN}

In this study, RBF and MLP are implemented to model the output of the electrical efficiency of the PV/T system collector. Seven hidden neurons were used for the training section in order to specify the target parameter by minimizing the distance of the forecasted and actual measured data. It is worth noting that the number of hidden neurons is seven. This number was obtained by trial and error method. For the ANN model we use ANN toolbox of MATLAB and also the Levenberg Marquardt (LM) algorithm was chosen according to its applicability in optimization problems in order to determine optimal weight and bias values. The mean squared error of the obtained forecasted values from the MLP practice is depicted in Figure 11. Moreover, Table 1 presents the optimum of bias and weight. 

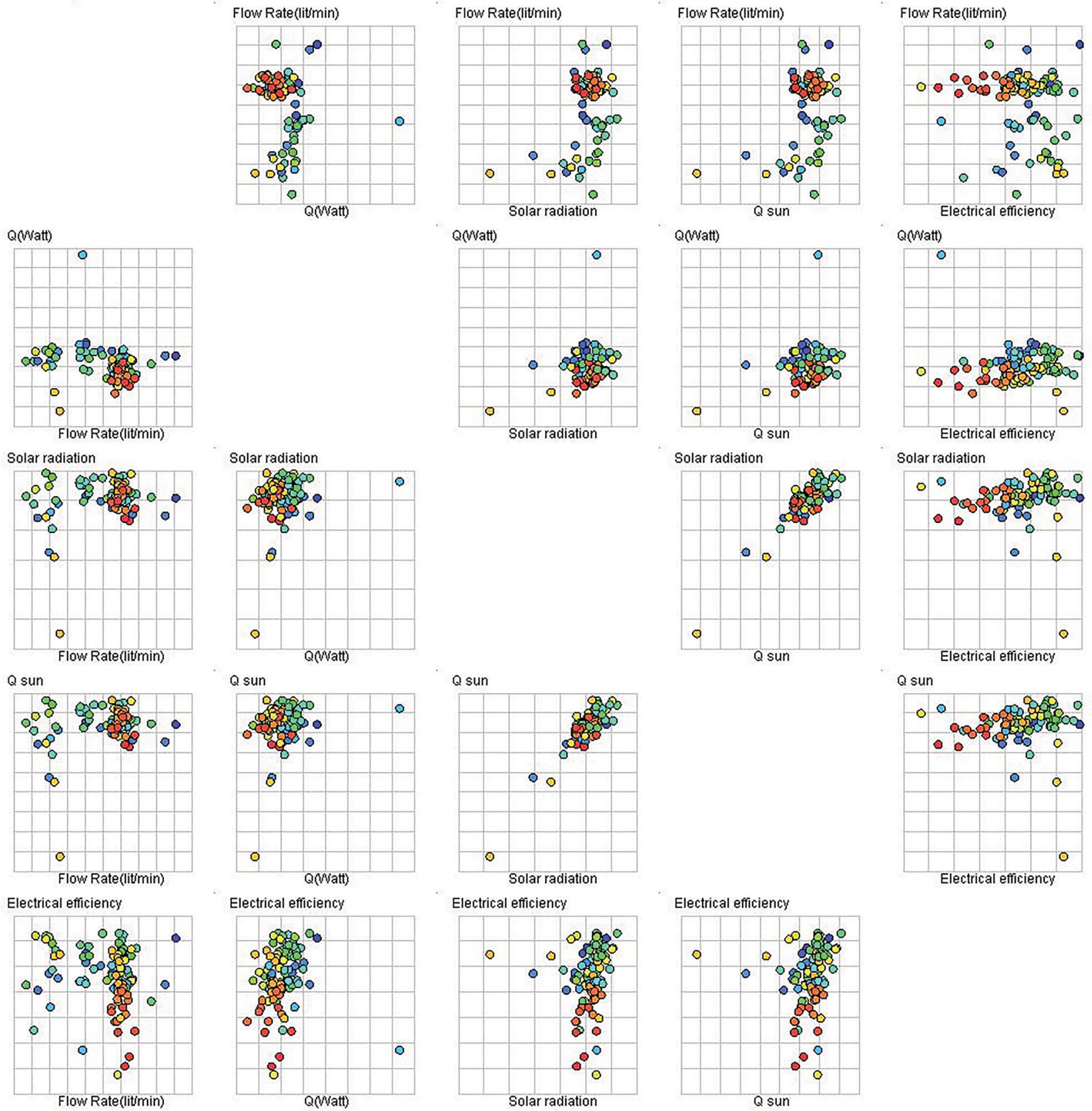

Figure 10. Scatter matrix plot for the studied parameters in the efficiency measurement of a PV/T collector.

Besides, to train the RBF-ANN model, the LevenbergMarquardt algorithm is used with 50 iterations. The training process of the radial basis network is regularly less time-consuming than the sigmoid or the linear network. The performance of the RBF-ANN method during various iterations is demonstrated in Figure 12.

\subsubsection{ANFIS method}

In facilitate the advancement of the ANFIS model, the Particle swarm optimization (PSO) approach was used. The overall numbers of ANFIS variables are dependent on clusters' number, $N_{c}$, variables' number, $N_{v}$, and the number of membership function variables $\left(N_{M F}\right)$ as follows:

$$
N_{T}=N_{c} \cdot N_{v} \cdot N_{M F}
$$

The membership function of this study is the Gaussian membership function. $\mathrm{Z}$ and $\sigma^{2}$ are the two membership function variables. The primary input parameters are sun heat, inlet temperature, flow rate, and solar radiation. Seven clusters are primarily considered. Hence, the overall number of ANFIS parameters is 84. In order to obtain the optimum status of the ANFIS parameters, the RMSE 


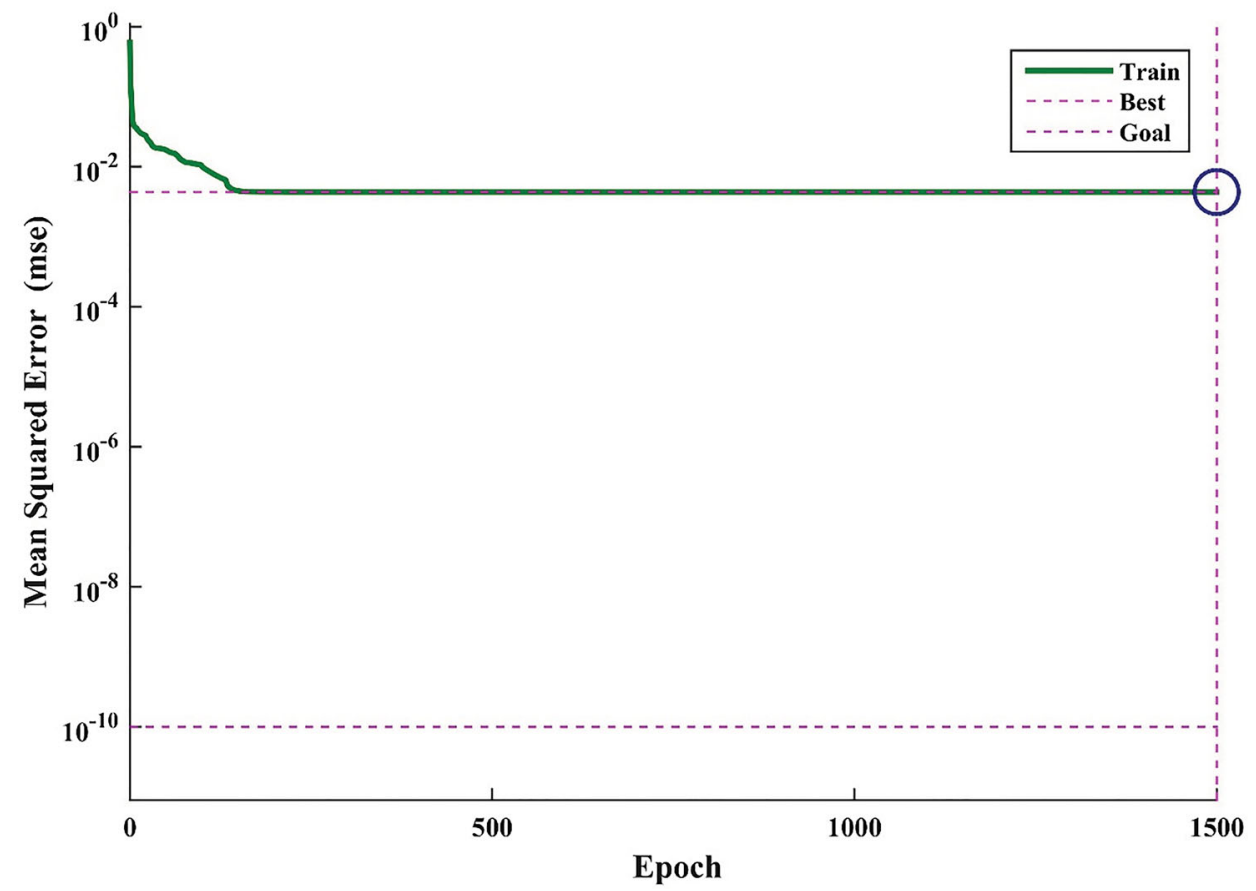

Figure 11. MLP-ANN performance during different iterations.

Table 1. Optimum values of weight and bias in the MLP-ANN model.

\begin{tabular}{|c|c|c|c|c|c|c|c|}
\hline \multicolumn{6}{|c|}{ Input layer } & \multicolumn{2}{|c|}{ Output layer } \\
\hline \multicolumn{5}{|c|}{ Weight } & \multirow{2}{*}{$\begin{array}{l}\text { Bias } \\
\text { b1 }\end{array}$} & \multirow{2}{*}{$\frac{\text { Weight }}{\text { Electrical Eff. }}$} & \multirow{2}{*}{$\begin{array}{c}\text { Bias } \\
\text { b2 }\end{array}$} \\
\hline Inlet T & Flow rate & Heat & Solar Rad. & The heat of Sun & & & \\
\hline-3.00217 & 14.62895 & 9.19011 & -6.14859 & -10.254 & 11.21392 & -0.77978 & 51.75337 \\
\hline 25.71744 & -43.7362 & -135.409 & 386.549 & 388.5208 & -811.641 & 1.63077 & \\
\hline 6.002147 & 30.00333 & -15.9983 & 5.146075 & 6.721965 & 4.233007 & -3.29637 & \\
\hline 0.022054 & -0.01171 & -0.01102 & -4.46868 & 4.423946 & -0.9196 & -166.279 & \\
\hline-77.2605 & 118.3238 & -20.377 & 72.74368 & 75.49725 & -152.927 & -1.55885 & \\
\hline 59.59531 & -54.9347 & 51.61157 & 15.50821 & 23.32499 & 5.853293 & -1.51761 & \\
\hline-12.356 & -25.3219 & 20.53642 & 0.310394 & 1.792913 & -11.9288 & -3.84421 & \\
\hline
\end{tabular}

between experimentally measured and the forecasted values is reflected as the cost function of the PSO algorithm Figure 13. The RMSE of each iteration is shown. The trained membership function for input data is illustrated in Figure 14.

\subsubsection{LSSVM}

The LSSVM approach employs two regulating variables in its algorithm. These variables are $\gamma$ and $\sigma^{2}$. The regulation variable is stated by $\gamma$, and the kernel variable is the RBF. Moreover, the LSSVM method is hybridized with GA to specify the optimum response of the introduced model.

\subsection{Models' evaluation}

Different statistical criteria such as R-squared, Root Mean Squared Error (RMSE) and etc. are applicable to evaluate the confidence, reliability and accuracy of the models (Qin \& Hiller, 2016; Qin, Hiller, \& Bao, 2013). In this research, the proposed approaches are evaluated based on various statistical methods as listed in the following:

$$
\text { Mean Squared Error }(\mathrm{MSE})=\frac{1}{N} \sum_{i=1}^{N}\left(H_{i}^{\text {exp. }}-H_{i}^{\text {cal. }}\right)^{2}
$$

Average Relative Deviation (ARD)(\%)

$$
=\frac{100}{N} \sum_{i=1}^{N} \frac{\left|H_{i}^{\text {exp. }}-H_{i}^{\text {cal. }}\right|}{H_{i}^{\text {exp. }}}
$$

Standard Deviation (STD)

$$
=\left(\frac{1}{N-1} \sum_{i=1}^{N}\left(H_{i}^{\text {exp. }}-H_{i}^{\text {cal. }}\right)^{2}\right)^{0.5}
$$




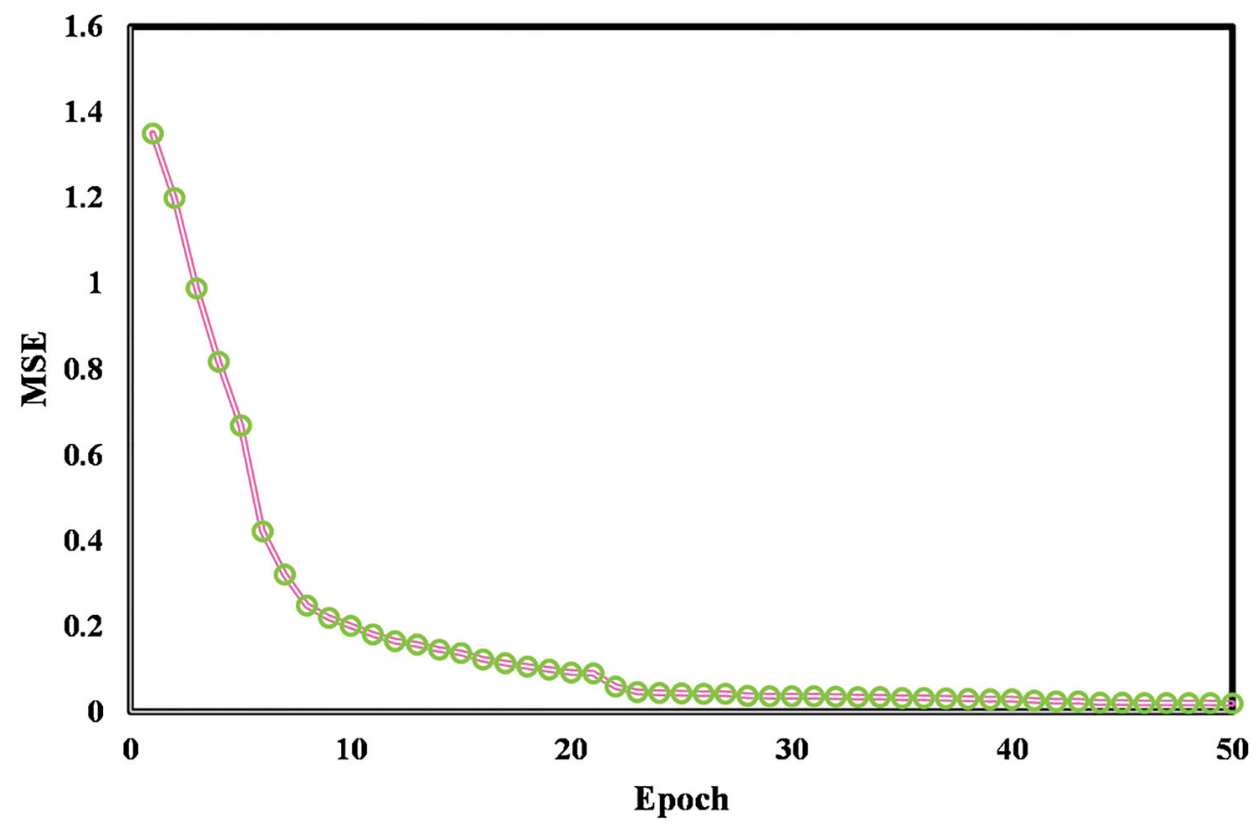

Figure 12. RBF-ANN performance during different iterations.

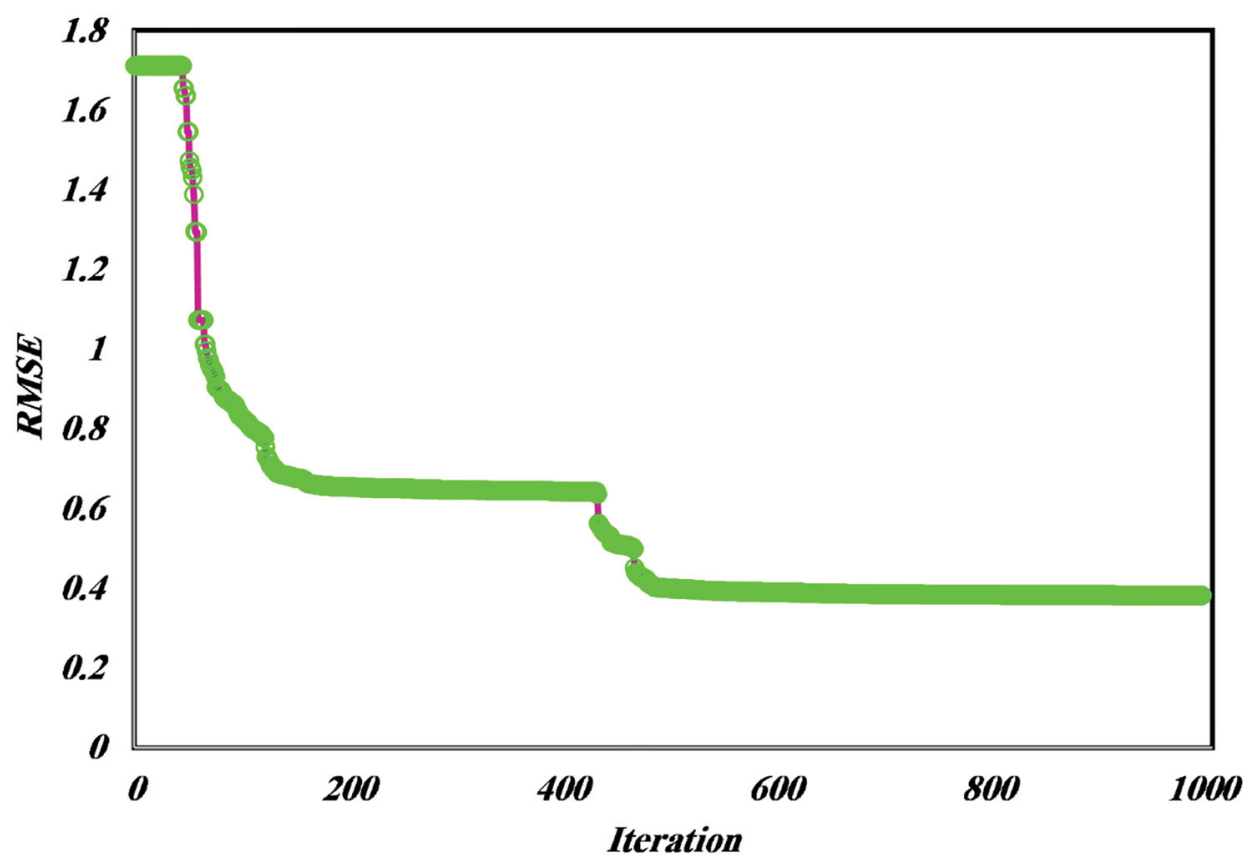

Figure 13. Applying the PSO algorithm at various iterations in the training stage of the ANFIS model.

Root Mean Squared Error (RMSE)

$$
=\left(\frac{1}{N} \sum_{i=1}^{N}\left(H_{i}^{\text {exp. }}-H_{i}^{\text {cal. }}\right)^{2}\right)^{0.5}
$$

$$
\begin{aligned}
& \text { Correlation Coefficient }\left(R^{2}\right) \\
& =1-\frac{\sum_{i=1}^{N}\left(H_{i}^{\text {exp. }}-H_{i}^{\text {cal. }}\right)^{2}}{\sum_{i=1}^{N}\left(H_{i}^{\text {exp. }}-\bar{H}^{\exp }\right)^{2}}
\end{aligned}
$$

Where $N$ denotes the quantity of data points. The superscripts of exp. and cal. are for values which experimentally and based on calculation were obtained, respectively. $\bar{H}^{\text {exp }}$ indicates the mean efficiency obtained through experimental measurements.

\section{Results and Discussion}

The obtained results from applying four introduced intelligent techniques are described in detail in Table 2. The used data set consists of 98 data points. 

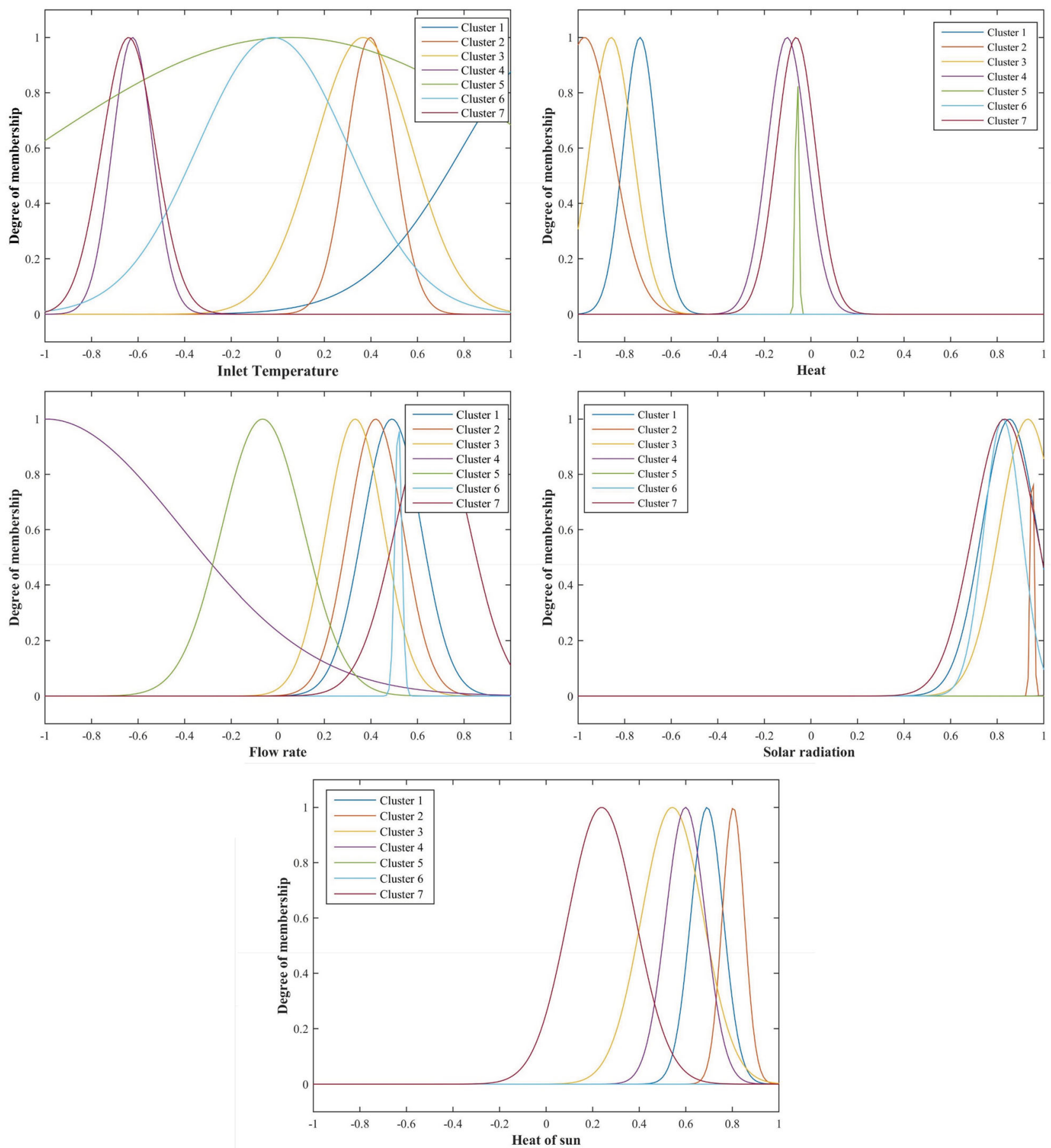

Figure 14. Fuzzy inference system for input variables: Training.

Figure 15 demonstrates the experimental plot for all investigated models, simultaneously. As it is monitored, all of the methods show an acceptable agreement with the trend of experimental values; because output line has passed most of the data well. However, the LSSVM approach is more precise based on the less deviation from experimental values in comparison with other methods; statistical calculations also confirm this result.

Figure 16 demonstrates the regression plot of the forecasted and experimentally measured values for the studied models. Based on this evaluation, it seems that most of the data are placed close to the $\mathrm{X}=\mathrm{Y}$ line. Figure 16 (a)-(c) illustrate the optimum fitting lines by using linear regression of experimentally measured data and forecasted values by machine-based methods. The LSSVM model seems to have better predictability than other models. R-squared value of the regression, which is used in several studies for evaluating the accuracy and reliability of the models (Qin, Zhang, \& Hiller, 2017), for the LSSVM model is equal to $0.9921 \& 0.9867$ for 
Table 2. Models' characteristics and further information.

\begin{tabular}{|c|c|c|c|}
\hline \multicolumn{2}{|l|}{ LSSVM } & \multicolumn{2}{|l|}{ ANFIS } \\
\hline Type & Value & Type & Value/comment \\
\hline Kernel function & RBF & Membership Function & Gaussian \\
\hline$\Gamma$ & 6942.0845 & No. of MF parameters & 84 \\
\hline$\sigma^{2}$ & 8.01234 & No. of clusters & 7 \\
\hline Quantity of training data & 74 & Quantity of training data & 74 \\
\hline Quantity of testing data & 24 & Quantity of testing data & 24 \\
\hline Population size & 100 & Population size & 50 \\
\hline Iteration & 1000 & Iteration & 1000 \\
\hline$C_{1}$ & 1 & $C_{1}$ & 1 \\
\hline $\mathrm{C}_{2}$ & 2 & $C_{2}$ & 2 \\
\hline \multicolumn{2}{|l|}{ MLP-ANN } & \multicolumn{2}{|l|}{ RBF-ANN } \\
\hline Type & Value/comment & Type & Value/comment \\
\hline Quantity of input neuron layer & 5 & Quantity of input neuron layer & 5 \\
\hline Quantity hidden neuron layer & 7 & Quantity of hidden neuron layer & 50 \\
\hline Quantity of output neuron layer & 1 & Quantity of output neuron layer & 1 \\
\hline Hidden layer activation function & Logsig & Optimization method & $\begin{array}{l}\text { Levenberg- } \\
\text { Marquardt }\end{array}$ \\
\hline Output layer activation function & Purelin & Quantity of training data used & 74 \\
\hline Optimization method & $\begin{array}{l}\text { Levenberg- } \\
\text { Marquardt }\end{array}$ & Quantity of testing data & 24 \\
\hline Quantity of training data for & 74 & Quantity of max iterations & 50 \\
\hline Quantity of testing data & 24 & & \\
\hline Quantity of max iterations & 1500 & & \\
\hline
\end{tabular}
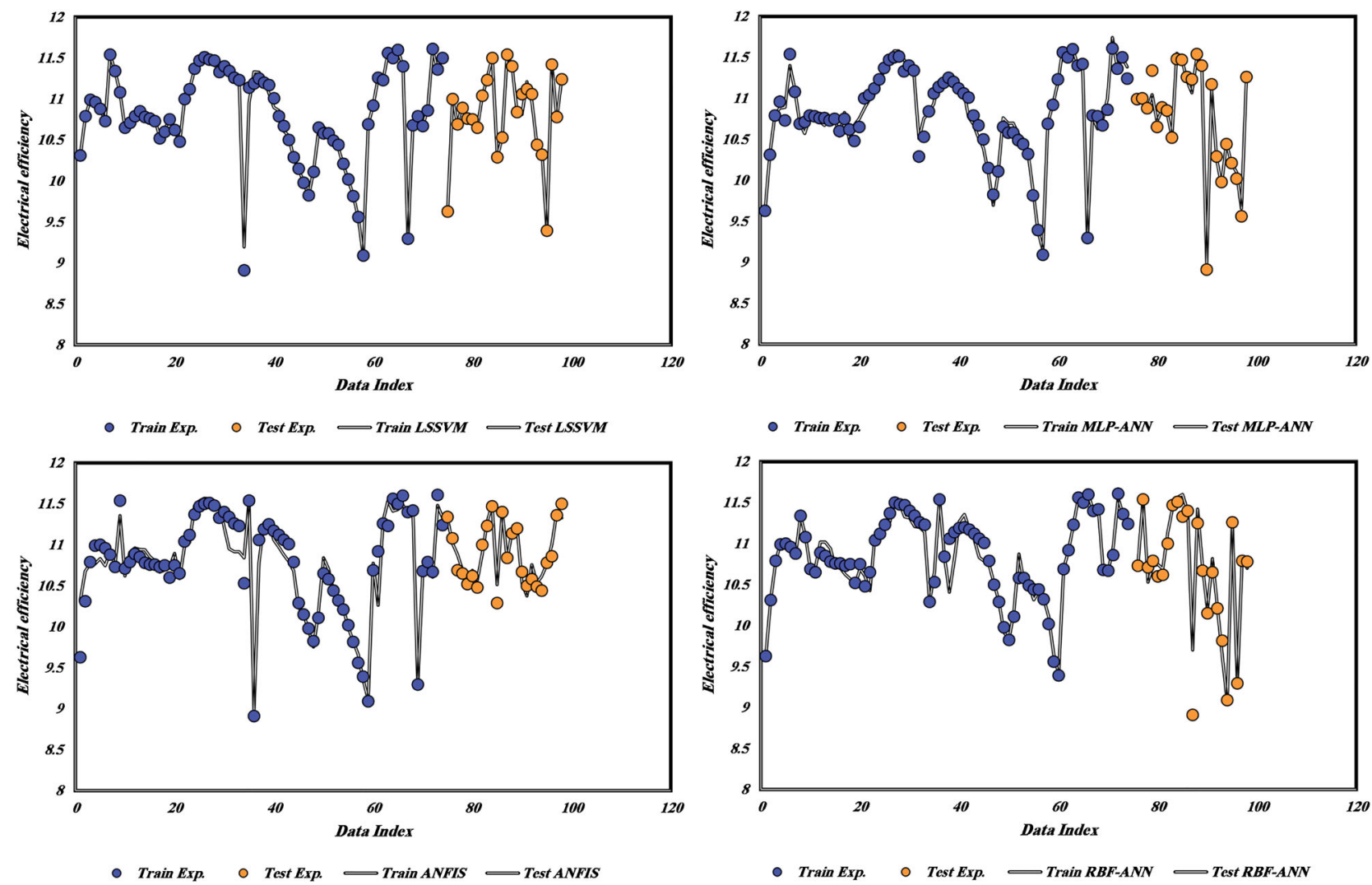

Figure 15. Experimental versus predicted electrical efficiency value.

training and testing data set. Also, these values are equal to $0.9182 \& 0.9225,0.9723 \& 0.9864$, and $0.9404 \& 0.9395$ for training and testing data set of ANFIS, MLP-ANN, and RBF-ANN models, respectively.
The deviation graph is another typical evaluation graph, which is used to compare the valued of the forecasted efficiency of the PV/T collector with the actual data resulted from the experiments. 

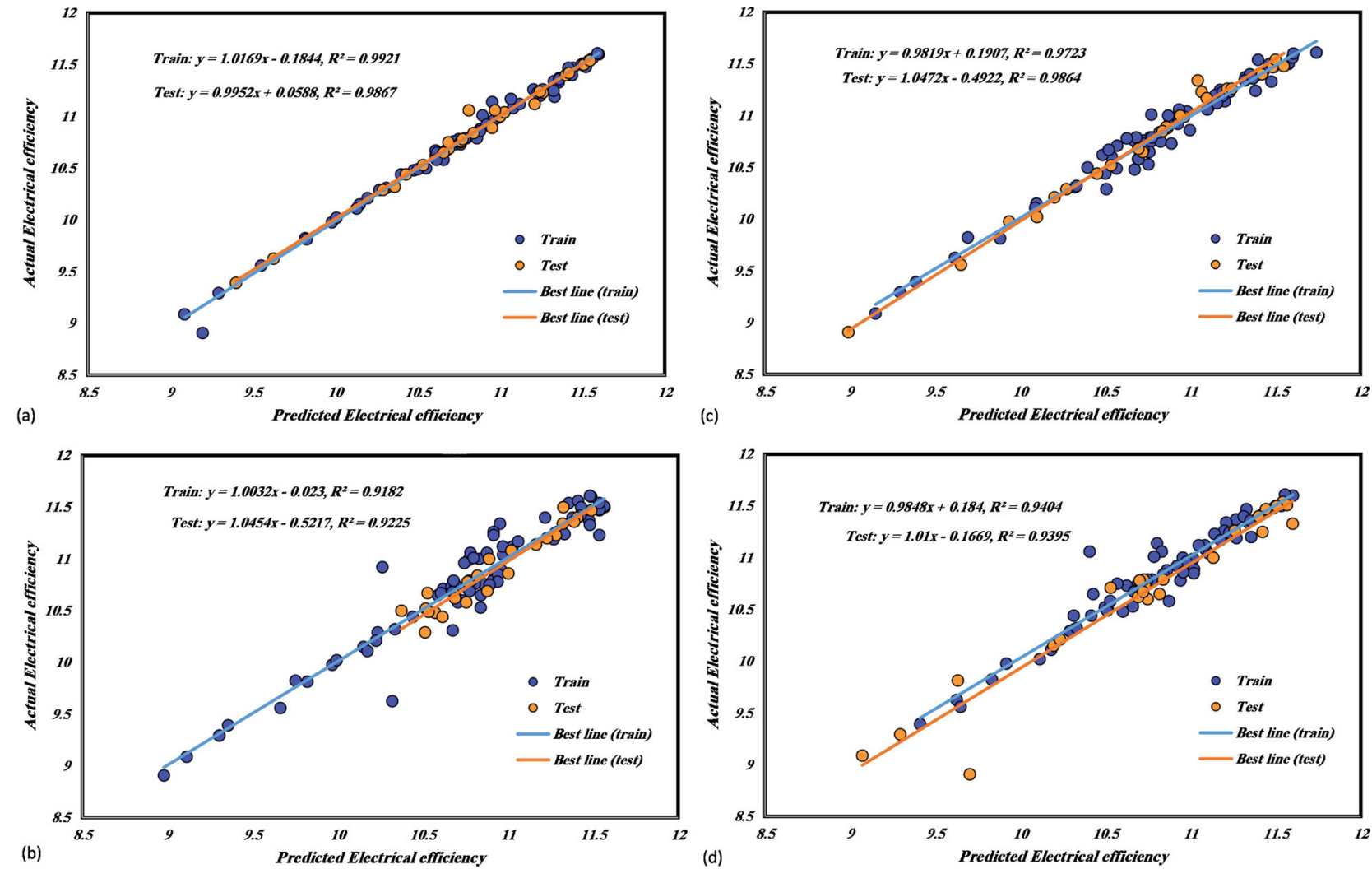

Figure 16. Regression plot of efficiency: experimental Vs. estimated (a) LSSVM, (b) ANFIS, (c) MLP-ANN, (d) RBF-ANN.
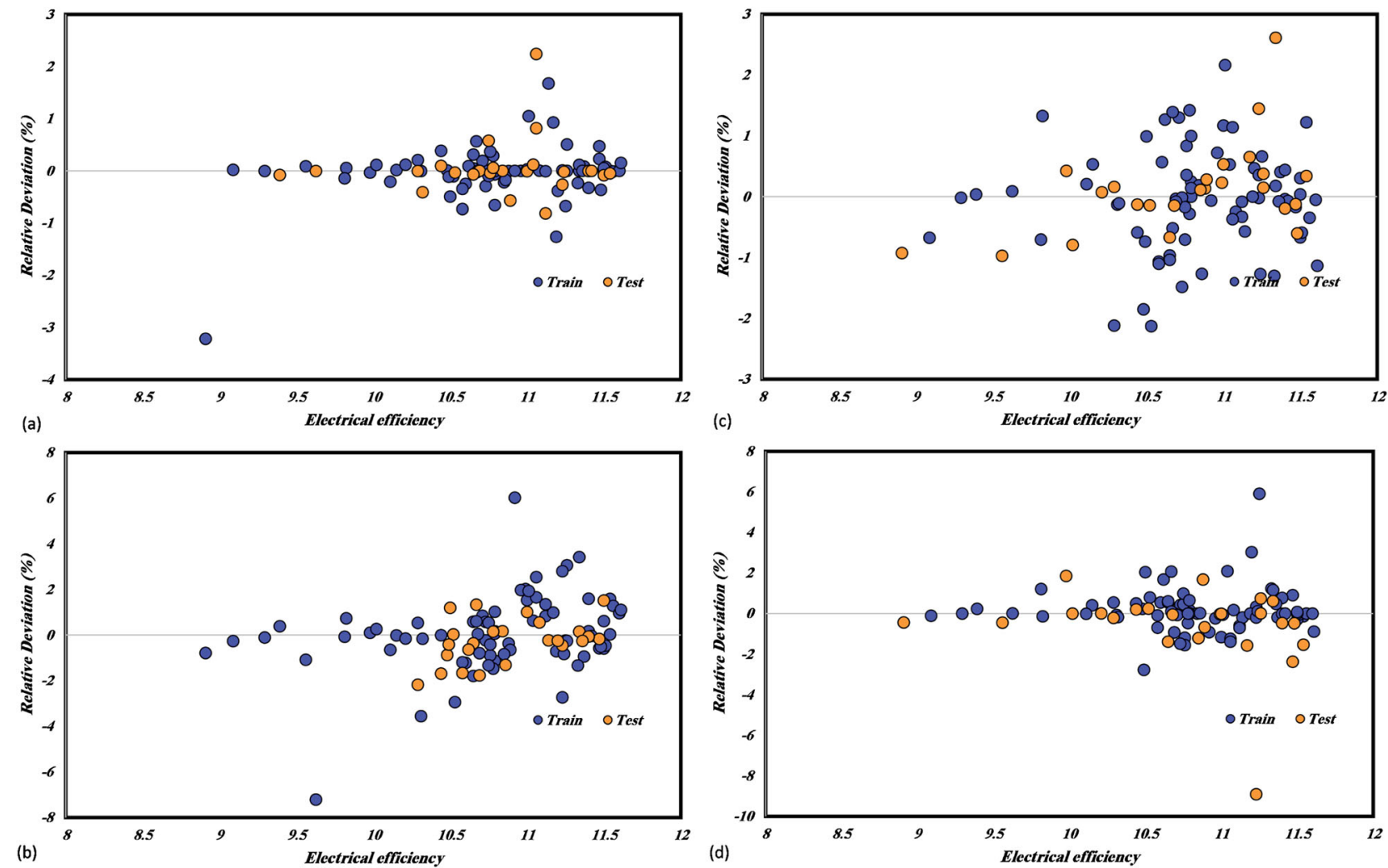

Figure 17. Relative deviations of efficiency: experiment Vs. predicted (a) LSSVM, (b) ANFIS, (c) MLP-ANN, (d) RBF-ANN. 
Figure 17 depicts the deviation diagram for all of the introduced models. Based on the deviation plot, the closeness of the data near the zero line is higher in the LSSVM approach, and therefore, the lower deviation results. The MLP-ANN, RBF-ANN, ANFIS, and LSSVM models resulted in the values of $0.6,0.75,1.03$, and 0.27 for the mean relative deviation of respectively. In order to examine the ability of the presented strategies, statistical error analyses are also performed for train, test, and overall data. Table 3 represents the results indicating that the proposed methods express precise estimation.

The following table compares the results of this work with previously published papers on the related subject (Table 4). Kalani and his colleagues did a machine learning work in predicting electrical efficiency of photovoltaic nanofluid based collector using RBF-ANN, MLP-ANN and ANFIS. Their model input parameters include ambient temperature, fluid inlet temperature and incident radiation. Rejeb and his colleagues used finite volume method to investigate the dynamic behavior of the photovoltaic/thermal sheet and tube collector, based on the energy balance. In addition, Dubey and his colleagues did analytical expression for determination of electrical efficiency of PV/T hybrid air collector. The results of these researchers' work are presented in the Table 4 . From this

Table 3. Error analysis through different criteria.

\begin{tabular}{lccccccc}
\hline Model & & MSE & RMSE & MRE & MAE & $\mathrm{R}^{2}$ & STD \\
\hline LSSVM & Test & 0.004 & 0.061 & 0.265 & 2.901981 & 0.987 & 0.055 \\
& Train & 0.003 & 0.053 & 0.253 & 2.678706 & 0.992 & 0.046 \\
& Total & 0.003 & 0.055 & 0.256 & 2.733386 & 0.991 & 0.048 \\
ANFIS & Test & 0.011 & 0.107 & 0.768 & 8.244855 & 0.922 & 0.069 \\
& Train & 0.032 & 0.178 & 1.123 & 12.13705 & 0.918 & 0.132 \\
& Total & 0.027 & 0.164 & 1.036 & 11.18386 & 0.918 & 0.120 \\
MLP-ANN & Test & 0.007 & 0.083 & 0.509 & 5.467401 & 0.986 & 0.063 \\
& Train & 0.008 & 0.091 & 0.634 & 6.832438 & 0.972 & 0.061 \\
& Total & 0.008 & 0.089 & 0.603 & 6.498143 & 0.976 & 0.061 \\
RBF-ANN & Test & 0.037 & 0.193 & 1.049 & 10.59609 & 0.940 & 0.165 \\
& Train & 0.015 & 0.123 & 0.656 & 7.124918 & 0.940 & 0.100 \\
& Total & 0.020 & 0.143 & 0.752 & 7.975 & 0.937 & 0.119 \\
\hline
\end{tabular}

Table 4. A comparison between the results of this paper with previously published works.

\begin{tabular}{lllc}
\hline Model & \multicolumn{1}{c}{ Reference } & RMSE (\%) & \multicolumn{1}{c}{$\mathrm{R}^{2}$} \\
\hline LSSVM & The present work & 0.055 & 0.991 \\
ANFIS & The present work & 0.164 & 0.918 \\
MLP-ANN & The present work & 0.089 & 0.976 \\
RBF-ANN & The present work & 0.143 & 0.937 \\
ANFIS & Kalani, Sardarabadi, \& & 0.2675 & 0.9896 \\
& $\quad$ Passandideh-Fard, (2017) & & \\
MLP-ANN & Kalani et al., (2017) & 0.3621 & 0.9363 \\
RBF-ANN & Kalani et al., (2017) & 0.2562 & 0.9906 \\
Numerical & Rejeb, Dhaou, \& Jemni, (2015) & 2.31224 & Not reported \\
$\quad$ investigation & & & \\
Analytical & Dubey, Sandhu, \& Tiwari, & $3.41-4.19$ & $0.806-0.849$ \\
\multicolumn{1}{c}{ investigation } & (2009) & & \\
\hline
\end{tabular}

table, the LSSVM model presented in this paper has the best ability to model the thermal performance of PV/T collector.

\subsection{Outlier Detection}

The trustworthiness of the employed models is exceptionally dependent on the experimentally measured data points (Rousseeuw \& Leroy, 2005). Outliers called to those data (individual or group) which their behaving trend is not following other data points. Therefore, one of the most important steps in the evolution of models is to detect and remove the outliers. Thus, to specify the outliers, the Leverage analysis by implementing standardized residuals $(\mathrm{R})$ is utilized. The outlying candidates explored through drawing William's plot, i.e. the graph of Rs against hat values $(\mathrm{H})$. The $\mathrm{H}$ is the diagonal arrays of the hat matrix and calculates as follows to specify the available space.

$$
H=X\left(X^{T} X\right)^{-1} X^{T}
$$

$X$ denotes a $[\ldots]_{n \times k}$ matrix where $n$ is the quantity of data and $k$ indicates the number of input variables. Feasible space is a squared region constrained to cut-off value on the vertical axis and also limited to the warning leverage value on the horizontal axis. Warning leverage is defined as:

$$
H^{*}=3 \frac{k+1}{n}
$$

$R=3$ is the recommended cut-off value. The lines of $R= \pm 3$ on the vertical axis limit the feasible region. On the other hand, the feasible space on the horizontal axis is specified between lines of $H=0$ and $H=H^{*}=0.09$. Those data that were outside of the acceptable range are called the Outlying. Based on William's plot, which is depicted in Figure 18, most of the data are placed in the acceptable range except for one data for all studied models.

\subsection{Sensitivity analysis}

In order to demonstrate the reliance of the objective of the study on input parameters, a sensitivity analysis is carried out. A relevancy factor of $-1<\mathrm{r}<+1$ is selected in the sensitivity analysis. As the $r$ is closer to unity states that the final objective parameter is highly affected by the input variables. The positive values of $r$ state the increasing effect of input parameters on the final objective, and negative values of $r$ represents a decreasing trend for the dependency of the target to the inputs. Relevancy factor 

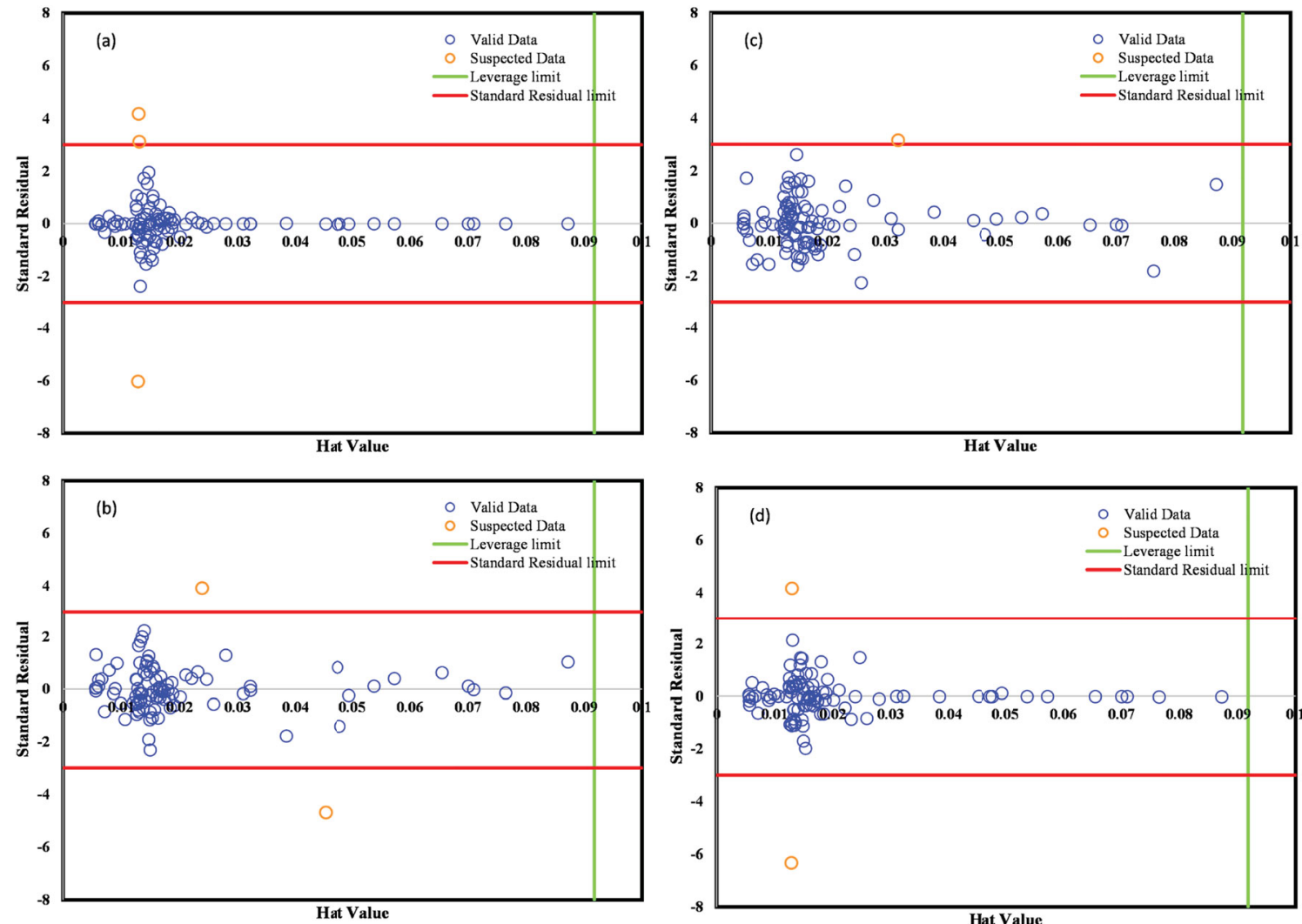

Figure 18. William's plot for: (a) LSSVM, (b) ANFIS, (c) MLP-ANN, (d) RBF-ANN.

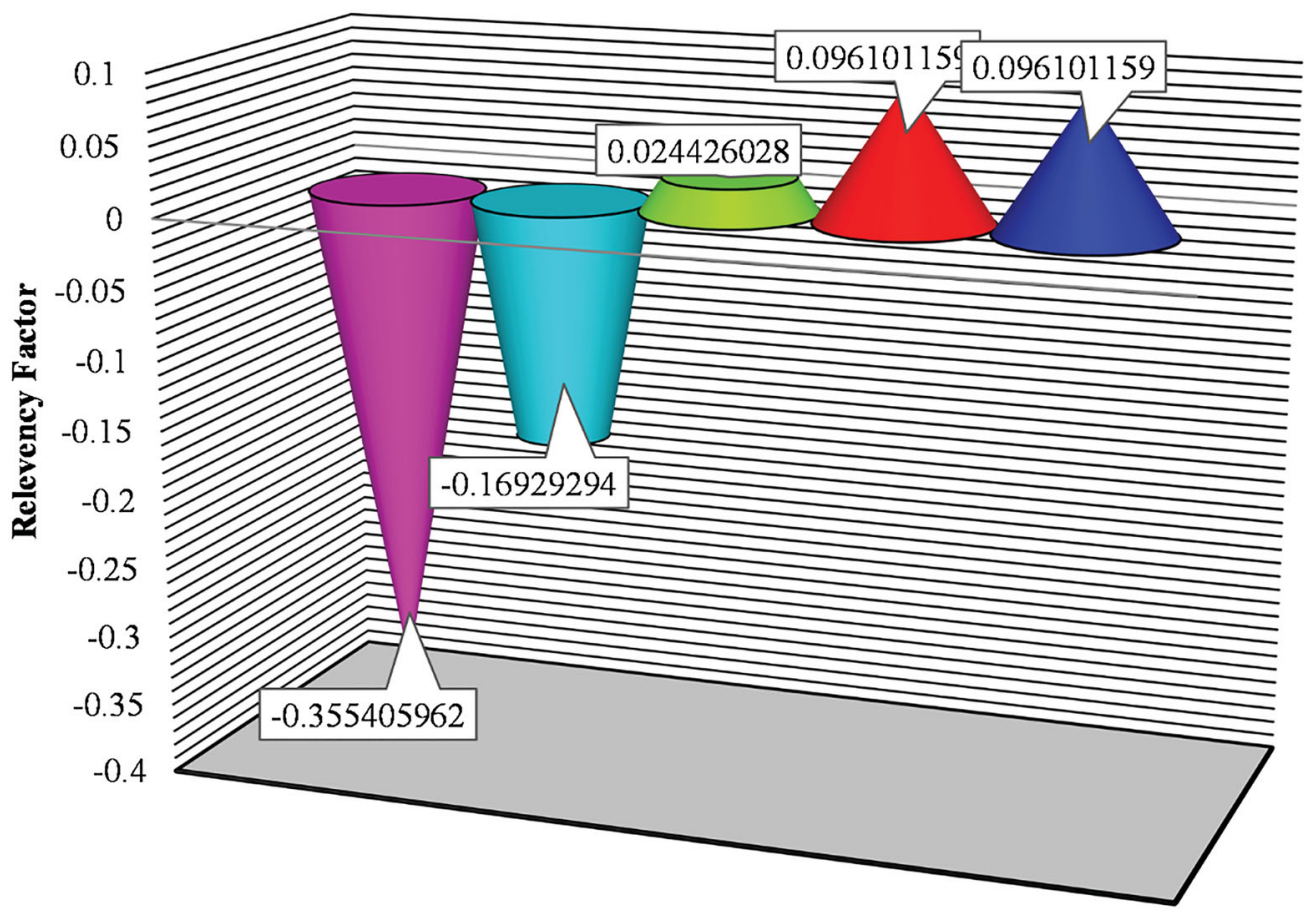

$\square$ Inlet Temp. $\quad \square$ Flow Rate(lit/min) $\quad \square \mathrm{Q}$ (Watt) $\quad \square$ Solar radiation $\square$ Q sun

Figure 19. Relevancy factors for input variables. 
is obtained as follows:

$$
r=\frac{\sum_{i=1}^{N}\left(X_{k, i}-\bar{X}_{k}\right)\left(y_{i}-\bar{y}\right)}{\sqrt{\sum_{i=1}^{N}\left(X_{k, i}-\bar{X}_{k}\right)^{2} \sum_{i=1}^{N}\left(y_{i}-\bar{y}\right)^{2}}}
$$

$X_{k, i}$ expresses the $\mathrm{i}^{\text {th }}$ input, $\bar{X}_{k}$ denotes the mean value of the $\mathrm{k}^{\text {th }}$ input, $y_{i}$ indicates the $\mathrm{i}^{\text {th }}$ output, and $\bar{y}$ represents the mean value of output. $N$ is the overall population of data. The relevancy factors for all of the input data are illustrated in Figure 19. The inlet temperature is monitored to be the most affecting variable in the efficiency of the PV/T system since the relevance factor of 0.36 was computed.

\section{Conclusion}

Machine learning methods of MLP-ANN, RBF-ANN, ANFIS, and LSSVM are utilized to establish a mathematical framework for improving the efficiency of PV/T collector through modeling the input parameters of inlet temperature, flow rate, heat, solar radiation, and sun heat. To this end, experimental measurements prepared by designing a solar collector system and a set of hundred data extracted. The trustworthiness of the models in precise estimation of the efficiency are represented with graphical and statistical approaches. In order to demonstrate the comprehensiveness of the models, the outlying recognition is performed. It is reported that the proposed LSSVM model outperfoms other models. R-squared $\left(\mathrm{R}^{2}\right)$ and Mean Squared Error (MSE) were 0.986 \& 0.007, 0.94 \& $0.037,0.922 \& 0.011$, and $0.987 \& 0.004$ for the four models, respectively. Based on the sensitivity analysis, the water inlet temperature has the most effect on the efficiency of the PV/T system since it has the most significant relevancy factor.

\section{Disclosure statement}

No potential conflict of interest was reported by the author(s).

\section{Funding}

We acknowledge the support of the German Research Foundation (DFG) and the Bauhaus-Universität Weimar within the open-access publishing programme. We also acknowledge the financial support of this work by the Hungarian State and the European Union under the EFOP-3.6.1-16-2016-00010 project and the 2017-1.3.1-VKE-2017-00025 project.

\section{ORCID}

Amir Mosavi (D) http://orcid.org/0000-0003-4842-0613 Shahaboddin Shamshirband (D) http://orcid.org/0000-00026605-498X

\section{References}

Ahmad, S. H. A., Saidur, R., Mahbubul, I. M., \& Al-Sulaiman, F. A. (2017). Optical properties of various nanofluids used in solar collector: A review. Renewable and Sustainable Energy Reviews, 73, 1014-1030.

Ahmadi, M. H., Ghazvini, M., Sadeghzadeh, M., Alhuyi Nazari, M., Kumar, R., Naeimi, A., \& Ming, T. (2018). Solar power technology for electricity generation: A critical review. Energy Science and Engineering. doi:10.1002/ese3.239

Al-Maamary, H. M. S., Kazem, H. A., \& Chaichan, M. T. (2017). Renewable energy and GCC states energy challenges in the 21st century: A review. International Journal of Computation and Applied Sciences, 2(1), 11-18.

Andrews, D. F. (1972). Plots of high-dimensional data. Biometrics, 28(1), 125-136. doi:10.2307/2528964

Baghban, A., Bahadori, M., Lemraski, A. S., \& Bahadori, A. (2015). Prediction of solubility of ammonia in liquid electrolytes using least square support vector machines. Ain Shams Engineering Journal. doi:10.1016/j.asej.2016.08. 006

Baghban, A., Kashiwao, T., Bahadori, M., Ahmad, Z., \& Bahadori, A. (2016). Estimation of natural gases water content using adaptive neuro-fuzzy inference system. Petroleum Science and Technology, 34(10), doi:10.1080/10916466.2016. 1176039

Baghban, A., Sasanipour, J., \& Zhang, Z. (2018). A new chemical structure-based model to estimate solid compound solubility in supercritical $\mathrm{CO}_{2}$. Journal of CO2 Utilization, 26, 262-270. doi:10.1016/j.jcou.2018.05.009

Bahadori, A., Baghban, A., Bahadori, M., Lee, M., Ahmad, Z., Zare, M., \& Abdollahi, E. (2016). Computational intelligent strategies to predict energy conservation benefits in excess air controlled gas-fired systems. Applied Thermal Engineering, 102, 432-446. doi:10.1016/j.applthermaleng.2016. 04.005

Bong, C. P. C., Ho, W. S., Hashim, H., Lim, J. S., Ho, C. S., Tan, W. S. P., \& Lee, C. T. (2017). Review on the renewable energy and solid waste management policies towards biogas development in Malaysia. Renewable and Sustainable Energy Reviews, 70, 988-998.

Brown, M., \& Harris, C. J. (1994). Neurofuzzy adaptive modelling and control. Texas, USA: Prentice Hall.

Burrows, W. R. (1997). CART regression models for predicting UV radiation at the ground in the presence of cloud and other environmental factors. Journal of Applied Meteorology, 36(5), 531-544.

Caner, M., Gedik, E., \& Keçebaş, A. (2011). Investigation on thermal performance calculation of two type solar air collectors using artificial neural network. Expert Systems with Applications, 38(3), 1668-1674.

Chau, K. (2017). Use of meta-heuristic techniques in rainfallrunoff modelling. Multidisciplinary Digital Publishing Institute.

Chuntian, C., \& Chau, K.-W. (2002). Three-person multiobjective conflict decision in reservoir flood control. European Journal of Operational Research, 142(3), 625631.

Dubey, S., Sandhu, G. S., \& Tiwari, G. N. (2009). Analytical expression for electrical efficiency of $\mathrm{PV} / \mathrm{T}$ hybrid air collector. Applied Energy, 86(5), 697-705.

Fotovatikhah, F., Herrera, M., Shamshirband, S., Chau, K.-W., Faizollahzadeh Ardabili, S., \& Piran, M. J. (2018). Survey of 
computational intelligence as basis to big flood management: Challenges, research directions and future work. Engineering Applications of Computational Fluid Mechanics, 12(1), 411-437.

Fuqiang, W., Ziming, C., Jianyu, T., Yuan, Y., Yong, S., \& Linhua, L. (2017). Progress in concentrated solar power technology with parabolic trough collector system: A comprehensive review. Renewable and Sustainable Energy Reviews, 79, 1314-1328.

Hajikhodaverdikhan, P., Nazari, M., Mohsenizadeh, M., Shamshirband, S., \& Chau, K. (2018). Earthquake prediction with meteorological data by particle filter-based support vector regression. Engineering Applications of Computational Fluid Mechanics, 12(1), 679-688.

Haratipour, P., Baghban, A., Mohammadi, A. H., Nazhad, S. H. H., \& Bahadori, A. (2017). On the estimation of viscosities and densities of $\mathrm{CO}_{2}$-loaded MDEA, MDEA + AMP, MDEA + DIPA, MDEA + MEA, and MDEA + DEA aqueous solutions. Journal of Molecular Liquids, 242, 146-159. doi:10.1016/j.molliq.2017.06.123

Haykin, S. (1994). Neural networks: A comprehensive foundation. Seattle, USA: Prentice Hall PTR.

Haykin, S. S., Haykin, S. S., Haykin, S. S., \& Haykin, S. S. (2009). Neural networks and learning machines (Vol. 3). Upper Saddle River, NJ, USA: Pearson.

Hussain, F., Othman, M. Y. H., Sopian, K., Yatim, B., Ruslan, H., \& Othman, H. (2013). Design development and performance evaluation of photovoltaic/thermal (PV/T) air base solar collector. Renewable and Sustainable Energy Reviews, 25, 431-441.

Kalani, H., Sardarabadi, M., \& Passandideh-Fard, M. (2017). Using artificial neural network models and particle swarm optimization for manner prediction of a photovoltaic thermal nanofluid based collector. Applied Thermal Engineering, 113, 1170-1177.

Kannan, N., \& Vakeesan, D. (2016). Solar energy for future world:-A review. Renewable and Sustainable Energy Reviews, 62, 1092-1105.

Kramer, K., \& Helmers, H. (2013). The interaction of standards and innovation: Hybrid photovoltaic-thermal collectors. Solar Energy, 98, 434-439.

Kumar, A., Prakash, O., \& Kaviti, A. K. (2017). A comprehensive review of Scheffler solar collector. Renewable and Sustainable Energy Reviews, 77, 890-898.

Lewis, N. S. (2016). Research opportunities to advance solar energy utilization. Science, 351(6271), aad1920.

Lin, C.-T., \& Lee, C. S. G. (1996). Neural fuzzy systems. Texas, USA: PTR Prentice Hall.

Marquez, R., \& Coimbra, C. F. M. (2011). Forecasting of global and direct solar irradiance using stochastic learning methods, ground experiments and the NWS database. Solar Energy, 85(5), 746-756.

Mitchell, T. M. (1997). Artificial neural networks. Machine Learning, 45, 81-127.

Modi, A., Bühler, F., Andreasen, J. G., \& Haglind, F. (2017). A review of solar energy based heat and power generation systems. Renewable and Sustainable Energy Reviews, 67, 1047-1064.

Moreno, A., Gilabert, M. A., \& Martínez, B. (2011). Mapping daily global solar irradiation over Spain: A comparative study of selected approaches. Solar Energy, 85(9), 2072-2084.
Pandey, K. M., \& Chaurasiya, R. (2017). A review on analysis and development of solar flat plate collector. Renewable and Sustainable Energy Reviews, 67, 641-650.

Pandey, A. K., Tyagi, V. V., Jeyraj, A., Selvaraj, L., Rahim, N. A., \& Tyagi, S. K. (2016). Recent advances in solar photovoltaic systems for emerging trends and advanced applications. Renewable and Sustainable Energy Reviews, 53, 859-884.

Park, J., \& Sandberg, I. W. (1993). Approximation and radial-basis-function networks. Neural Computation, 5(2), 305-316.

Pelckmans, K., Suykens, J. A. K., Gestel, T. V., De Brabanter, J., Lukas, L., Hamers, B., .. . Vandewalle, J. (n.d.). LS-SVMlab: a MATLAB/C toolbox for Least Squares Support Vector Machines. Retrieved from ftp://ftp.esat.kuleuven.be/stadius/ kpelckma/kp02-44.pdf.

Podestá, G. P., Núñez, L., Villanueva, C. A., \& Skansi, M. A. (2004). Estimating daily solar radiation in the Argentine Pampas. Agricultural and Forest Meteorology, 123(1-2), 41-53.

Qin, Y. (2015). A review on the development of cool pavements to mitigate urban heat island effect. Renewable and Sustainable Energy Reviews, 52, 445-459. doi:10.1016/J.RSER.2015. 07.177

Qin, Y. (2016). Pavement surface maximum temperature increases linearly with solar absorption and reciprocal thermal inertial. International Journal of Heat and Mass Transfer, 97, 391-399. doi:10.1016/J.IJHEATMASSTRANSFER.2016. 02.032

Qin, Y., \& Hiller, J. E. (2016). Water availability near the surface dominates the evaporation of pervious concrete. Construction and Building Materials, 111, 77-84. doi:10.1016/J.CONBUILDMAT.2016.02.063

Qin, Y., Hiller, J. E., \& Bao, T. (2013). Modeling cold region ground temperatures with a heat flux upper boundary model. Journal of Cold Regions Engineering, 27(1), 29-43. doi:10.1061/(ASCE)CR.1943-5495.0000051

Qin, Y., Liang, J., Luo, Z., Tan, K., \& Zhu, Z. (2016). Increasing the southern side-slope albedo remedies thermal asymmetry of cold-region roadway embankments. Cold Regions Science and Technology, 123, 115-120. doi:10.1016/J.COLDREGIO NS.2015.12.006

Qin, Y., Liang, J., Tan, K., \& Li, F. (2016). A side by side comparison of the cooling effect of building blocks with retro-reflective and diffuse-reflective walls. Solar Energy, 133, 172-179. doi:10.1016/J.SOLENER.2016.03.067

Qin, Y., Liang, J., Tan, K., \& Li, F. (2017). The amplitude and maximum of daily pavement surface temperature increase linearly with solar absorption. Road Materials and Pavement Design, 18(2), 440-452. doi:10.1080/14680629.2016.11 62732

Qin, Y., Zhang, M., \& Hiller, J. E. (2017). Theoretical and experimental studies on the daily accumulative heat gain from cool roofs. Energy, 129, 138-147. doi:10.1016/J.ENERGY.2017. 04.077

Ramezanizadeh, M., Ahmadi, M. A., Ahmadi, M. H., \& Alhuyi Nazari, M. (2018). Rigorous smart model for predicting dynamic viscosity of Al2O3/water nanofluid. Journal of Thermal Analysis and Calorimetry, 1. doi:10.1007/s10973018-7916-1

Ramezanizadeh, M., Alhuyi Nazari, M., Ahmadi, M. H., Lorenzini, G., \& Pop, I. (2019). A review on the applications of 
intelligence methods in predicting thermal conductivity of nanofluids. Journal of Thermal Analysis and Calorimetry, 1-17. doi:10.1007/s10973-019-08154-3

Ramezanizadeh, M., Nazari, M. A., Ahmadi, M. H., Lorenzini, G., Kumar, R., \& Jilte, R. (2018). A review on the solar applications of thermosyphons. Mathematical Modelling of Engineering Problems, 5(4), 275-280. doi:10.18280/mmep. 050401

Rejeb, O., Dhaou, H., \& Jemni, A. (2015). A numerical investigation of a photovoltaic thermal (PV/T) collector. Renewable Energy, 77, 43-50.

Rousseeuw, P. J., \& Leroy, A. M. (2005). Robust regression and outlier detection (Vol. 589). John wiley \& sons.

Schalkoff, R. J. (1997). Artificial neural networks (Vol. 1). New York: McGraw-Hill.

Sijm, J. P. M. (2017). Cost and revenue related impacts of integrating electricity from variable renewable energy into the power system-A review of recent literature. Policy Studies, 2016, 2015.

Suykens, J. A. K., Van Gestel, T., De Brabanter, J., De Moor, B., \& Vandewalle, J. (2002). Least squares support vector machines. Singapore: World Scientific Publishing.

Taherei Ghazvinei, P., Hassanpour Darvishi, H., Mosavi, A., Yusof, K. bin W., Alizamir, M., Shamshirband, S., \& Chau, K. (2018). Sugarcane growth prediction based on meteorological parameters using extreme learning machine and artificial neural network. Engineering Applications of Computational Fluid Mechanics, 12(1), 738-749.
Tso, G. K. F., \& Yau, K. K. W. (2007). Predicting electricity energy consumption: A comparison of regression analysis, decision tree and neural networks. Energy, 32(9), 1761-1768.

Twidell, J., \& Weir, T. (2015). Renewable energy resources. Seattle, USA: Routledge.

Vapnik, V., Golowich, S. E., \& Smola, A. J. (1997). Support vector method for function approximation, regression estimation and signal processing. In Advances in neural information processing systems (pp. 281-287).

Varol, Y., Koca, A., Oztop, H. F., \& Avci, E. (2010). Forecasting of thermal energy storage performance of Phase Change Material in a solar collector using soft computing techniques. Expert Systems with Applications, 37(4), 27242732.

Wagh, S., \& Walke, P. V. (2017). Review on wind-solar hybrid power system. International Journal of Research In Science \& Engineering, 3, 112-132.

Wasserman, P. D. (1993). Advanced methods in neural computing. Florida, USA: John Wiley \& Sons, Inc.

Wu, C. L., \& Chau, K. W. (2011). Rainfall-runoff modeling using artificial neural network coupled with singular spectrum analysis. Journal of Hydrology, 399(3-4), 394-409. doi:10.1016/J.JHYDROL.2011.01.017

Ye, J., \& Xiong, T. (2007). Svm versus least squares svm. In International Conference on Artificial Intelligence and Statistics (pp. 644-651).

Yegnanarayana, B. (2009). Artificial neural networks. New York, USA: PHI Learning Pvt. Ltd. 